\title{
Lesões parasitárias encontradas em bovinos abatidos para consumo humano ${ }^{1}$
}

\author{
Bianca Tessele $^{2}$, Juliana S. Brum ${ }^{2}$ e Claudio S.L. Barros ${ }^{3 *}$
}

\begin{abstract}
Tessele B., Brum J.S. \& Barros C.S.L. 2013. [Parasitic lesions observed in cattle slaughtered for human consumption.] Lesões parasitárias encontradas em bovinos abatidos para consumo humano. Pesquisa Veterinária Brasileira 33(7):873-889. Departamento de Patologia, Universidade Federal de Santa Maria, Camobi, Santa Maria, RS 97105-900, Brazil. E-mail: claudioslbarros@uol.com.br

During a period of 28 months (January 2011-April 2013) periodical visits were made to four cattle slaughter houses to collect samples of lesions found in cattle slaughtered for human consumption. Three hundred and three lesions were collected, $25 \%$ of which were caused by six different parasites: The metacestodes of Echinocccus granulosus (hydatid cysts), Fasciola hepatica, the metacestodes of Taenia saginata (Cysticercus bovis), Oesophagostomum radiatum, Eurythrema coelomaticum, and Paramphistomum cervi. Gross and microscopic aspects of the lesions caused by these worms are profusely illustrated and a detailed description of both pathological aspects, gross and microscopic, are provide in the hopes that the neophyte veterinary meat inspector can benefit from them in the task of recognition and interpretation of the significance of these lesion both to human and animal health. In regard to the two latter objectives, the life cycle, and the pathogenicity to the animal and human hosts, and the destination of the affected carcass or organ in the line of inspection are discussed for each parasite.
\end{abstract}

INDEX TERMS: Parasite induce lesion in cattle, abattoir survey, hydatid cysts, Fasciola hepatica, bovine cysticercosis, Oesophagostomum radiatum, Eurythrema coelomaticum, Paramphistomum cervi, diseases of cattle.

RESUMO.- Durante um período de 28 meses (janeiro 2011-abril 2013) foram feitas visitas periódicas a quarto abatedouros frigoríficos de bovinos para colher lesões regularmente encontradas em bovinos abatidos para consumo humano. Trezentas e três lesões foram colhidas, $25 \%$ das quais eram causadas por seis parasitas diferentes: o metacestoide de Echinocccus granulosus (cisto hidático), Fasciola hepatica, o metacestoide de Taenia saginata (Cysticercus bovis), Oesophagostomum radiatum, Eurythrema coelomaticum e Paramphistomum cervi. Os aspectos macro e microscópicos causados por esses vermes são profusa-

\footnotetext{
${ }^{1}$ Recebido em 17 de maio de2013.

Aceito para publicação em 12 de junho de 2013.

Parte da Dissertação de Mestrado do primeiro autor.

${ }^{2}$ Programa de Pós-Graduação em Medicina Veterinária, área de concentração em Patologia Veterinária, Centro de Ciências Rurais (CCR), Universidade Federal de Santa Maria (UFSM), Camobi, Santa Maria, RS 97105900, Brasil.

${ }^{3}$ Departamento de Patologia, UFSM, Santa Maria, RS. Pesquisador 1A do CNPq. *Autor para correspondência: claudioslbarros@uol.com.br
}

mente ilustrados e uma descrição macro e microscópicadas lesões é fornecida na esperança de auxiliar o inspetor de carnes iniciante na tarefa de reconhecer e interpretar o significado dessas lesões tanto para a saúde animal quanto para a saúde humana. Com respeito a esses últimos objetivos, o ciclo evolutivo, e os efeitos nos hospedeiros animal e humano, e ainda a destinação da carcaça ou órgão afetado na linha de inspeção, são discutidos para cada parasita.

TERMOS DE INDEXAÇÃO: Lesões induzidas por parasitas em bovinos, pesquisa em abatedouro, cisto hidático, Fasciola hepatica, cisticercose bovina, Oesophagostomum radiatum, Eurythrema coelomaticum, Paramphistomum cervi, doenças de bovinos.

\section{INTRODUÇÃO}

$\mathrm{O}$ abatedouro frigorífico constitui relevante instrumento de diagnóstico de enfermidades, entre elas as de caráter zoonótico (Ungar et al. 1990). A inspeção nos abatedouros consiste em observar ou examinar a carcaça e os órgãos, à busca de condições anormais que, de alguma maneira, limitem ou impeçam o aproveitamento do produto ou maté- 
ria prima para o consumo humano (Prata \& Fukuda 2001). Além disso, com a inspeção procura-se proteger a indústria de perdas econômicas devido ao fornecimento de produtos de qualidade inferior (Infante Gil \& Costa Durão 1990).

Estudos desenvolvidos em diversos países demonstraram que a falta de acurácia na linha de inspeção tem elevado os custos de produção dos frigoríficos (Alberton 2000). Uma grande dificuldade enfrentada pelos inspetores oficiais em estabelecimentos de abate tem sido relacionada à falta de segurança em diagnosticar as diversas enfermidades e, em seguida, estabelecer o destino apropriado e confiável para as carcaças e vísceras desses animais (Freitas 1999). Por exemplo, não há dificuldade para o diagnóstico macroscópico de Cysticercus bovis no seu estádio larval vivo. Todavia, este diagnóstico pode ser difícil nos casos em que os metacestoides estejam mortos e calcificados. Nestas circunstâncias, o apoio do exame histopatológico pode ser de grande valia na diferenciação de lesões (Costa et al. 2006), como as provocadas pela migração de larvas de helmintos, que não o cisticerco, e até mesmo a tuberculose (Monlux \& Monlux 1972, Kelly 1993).

As principais condenações de abatedouros de bovinos descritas na literatura ocorrem devido a lesões associadas com cisticercose (Marques et al. 2008), hidatidose (Cabrera et al. 2002) e fasciolose (Dutra et al. 2010), todas doenças parasitárias. 0 objetivo desse trabalho é descrever a epidemiologia, as lesões macroscópicas e microscópicas e o destino adequado de carcaças e órgãos afetados com os principais parasitas encontrados em abatedouros de bovinos localizados em diferentes regiões do Rio Grande do Sul e na cidade de Araguaína, em Tocantins.

\section{MATERIAL E MÉTODOS}

De janeiro de 2011 a abril de 2013 amostras de lesões de bovinos destinados ao abate foram recebidas no Laboratório de Patologia Veterinária da Universidade Federal de Santa Maria e visitas periódicas a abatedouros foram realizadas para colher amostras das lesões observadas na linha de abate. Os materiais eram provenientes de frigoríficos localizados em Santa Maria, região Central do Estado; de um frigorífico de Santo Ângelo, região Noroeste e de um frigorífico de Uruguaiana, localizado na Fronteira Oeste do Estado do Rio Grande do Sul. Amostras também foram colhidas em frigoríficos localizados em Araguaína, município da região norte do Estado de Tocantins. Todo o material foi fotografado e fragmentos de vários órgãos foram colhidos e fixados em formal a 10\%. Após a fixação, os materiais foram encaminhados ao processamento histológico de rotina, para avaliação das lesões histológicas.

Quadro 1. Discriminação dos 77 casos de lesões parasitárias encontrados em bovinos abatidos em matadouro-frigorífico

\begin{tabular}{lccl}
\hline \multicolumn{1}{c}{ Lesão } & Número \% sobre o total & \multicolumn{1}{c}{ Localização anatômica } \\
& \multicolumn{3}{c}{$\begin{array}{c}\text { de lesões para- } \\
\text { sitárias encon- } \\
\text { tradas }\end{array}$} \\
\hline Cisto hidático & 30 & 39 & $\begin{array}{l}\text { Fígado, pulmão, coração, mús- } \\
\text { culo esquelético, rim e osso }\end{array}$ \\
Fasciolose & 21 & 27 & Fígado e pulmão \\
Cisticercose & 15 & 19 & Músculo esquelético, coração \\
Esofagostomose & 8 & $10,5 \%$ & Parede do intestino, omento \\
Euritrematose & 2 & 3 & Pâncreas \\
Paramfistomíase & 1 & 1,5 & Rúmen
\end{tabular}

\section{RESULTADOS E DISCUSSÃO}

Durante um período de 28 meses foram colhidas, em matadouros-frigoríficos, 303 amostras de lesões em tecidos de bovinos de diferentes regiões do Brasil. Dessas 303 amostras, 77 (25\%) eram lesões provocadas por seis parasitas diferentes. 0 tipo e o número de lesões, suas porcentagens calculadas sobre o número total de lesões e as suas localizações anatômicas estão no Quadro 1. No Quadro 2 aparecem os destinos dados às lesões parasitárias e às carcaças de bovinos pela Inspeção Federal (Brasil 1980).

\section{Quadro 2. Destinos dados às lesões parasitárias e às carcaças de bovinos pela Inspeção Federal (Fontes: Brasil 1980, Santurio et al. 1988, Grist 2008)}

Lesão Destino

Hidatidose Condenação do órgão e partes afetadas, carcaça liberada. A carcaça poderá ser condenada caso houver caquexia concomitante

Fasciolose Condenação do(s) órgão(s) afetado(s). Carcaça liberada. Em alguns frigoríficos, partes não afetadas ou pouco afetadas do fígado são liberadas para manufatura de ração de pequenos animais.

Cisticercose 1 cisto calcificado = carcaça liberada in natura

1 cisto vivo = liberação da carcaça após tratamento pelo frio $\left(-10^{\circ} \mathrm{C}\right.$ por 10 dias $)$, pelo calor $\left(60^{\circ} \mathrm{C}\right)$ ou alternativamente, salga por 21 dias

2 cistos calcificados $=1$ cisto vivo

Infestação generalizada (mais de 3 cistos em cerca de um palmo de extensão) = carcaça condenada

Esofagostomose Os intestinos afetados por nódulos de esofagostomíneos são condenados, a carcaça é liberada. Se os nódulos forem em pequeno número e puderem ser extirpados os intestinos podem ser aproveitados totalmente ou parcialmente

Euritrematose Condenação do órgão afetado. Carcaça liberada.

Paranfistomíase Não há menção do destino dos órgãos afetados por Paramphistomum spp. no Regulamento de Inspeção Industrial e Sanitária dos Produtos de Origem Animal (RIISPOA). Por bom senso e com base no procedimento em outros países, os rúmens e retículos parasitados devem ser condenados.

\section{Hidatidose}

Hidatidose é a condição (doença) em que um "cisto hidático" ou "hidátide" (metacestoide [forma larval] de Echinococcus granulosus) desenvolve-se em vários órgãos, mas principalmente no fígado e pulmão (Brown et al. 2007, Taylor et al. 2007, Brown 2009). E. granulosus é um cestoide (classe Cestoda, Família Taeniidae) que parasita o intestino delgado do cão ou outros canídeos selvagens (os hospedeiros definitivos), tem 2-8 $\mathrm{mm}$ de comprimento. Consistem da cabeça, escólice e 2-4 segmentos ou proglotes (Taylor et al. 2007, Brown 2009). Os ovos contêm embrião (oncosfera) rodeado por uma casca denominada embrióforo. As oncosferas possuem ganchos orais e são eliminadas nas fezes e podem ficar no ambiente, fora do hospedeiro, por até dois anos. Os hospedeiros intermediários de E. granulosus incluem ovinos, bovinos e seres humanos (Brown et al. 2007, Taylor et al. 2007, Brown 2009). 0 ovo embrionado eliminado nas fezes do cão é ingerido por um dos hospedeiros intermediários (Fig.1), a oncosfera liberada dos ovos no intestino do hospedeiro intermediário segue pela circulação sanguínea até o fígado, ou pela circulação linfática até 


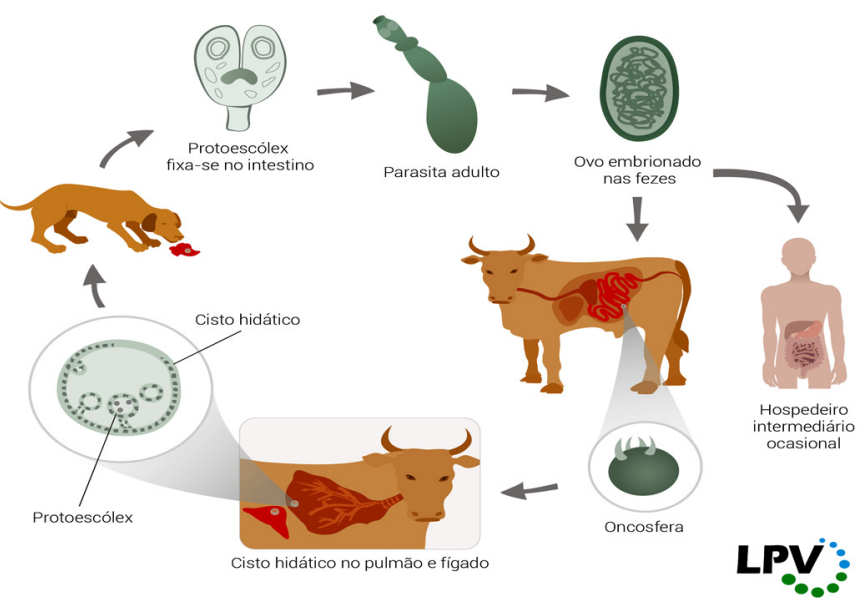

Fig.1. Ciclo de vida de Echinococcus granulosus. 0 cão é o hospedeiro definitivo e se contamina ingerindo vísceras (em nosso meio geralmente de ovinos). Os protoescólices liberados do cisto fixam-se no intestino e desenvolvem-se no cestoide adulto que tem cerca de 2-8mm de comprimento e apenas 4-5 segmentos, dos quais apenas o último é grávido. 0 período pré-patente no hospedeiro definitivo é de 40-50 dias; após esse período apenas um segmento grávido é eliminado por semana. $\mathrm{O}$ ovo embrionado eliminado nas fezes do hospedeiro definitivo é ingerido por um dos hospedeiros intermediários, os quais incluem bovinos e seres humanos. Após a ingestão pelo hospedeiro intermediário, a oncosfera liberada dos ovos no intestino do hospedeiro intermediário segue pela circulação sanguínea até o fígado, ou pela circulação linfática até o pulmão. Esses são os locais mais comuns do desenvolvimento dos metacestoides. No entanto, ocasionalmente as oncosferas escapam para a circulação sistêmica e se desenvolvem em outros órgãos como baço, coração, osso, encéfalo e tecido subcutâneo. 0 desenvolvimento do cisto hidático no hospedeiro intermediário é lento e a maturidade é alcançada em 6-12 meses. No fígado e nos pulmões o cisto atinge $5-10 \mathrm{~cm}$. A cápsula do cisto compreende uma membrana externa laminada e um epitélio germinativo interno de onde, quando o desenvolvimento do cisto está quase completo, brotam cápsulas prolígeras cada uma delas contendo vários escólices. Muitas dessas cápsulas destacam-se e os escólices aparecem livres no líquido da hidátide. Isso é comumente referido como areia hidática. Algumas vezes cistos filhos são formados dentro do cisto materno ou externamente ao cisto, no tecido circunvizinho; neste último caso eles podem ser levados a outras partes do organismo para formar novos cistos hidáticos. Quando o hospedeiro definitivo ingere tecidos de hospedeiros intermediários contendo cistos viáveis, o ciclo recomeça.

o pulmão. Esses são os locais mais comuns do desenvolvimento dos metacestoides. No entanto, ocasionalmente as oncosferas escapam para a circulação sistêmica e se desenvolvem em outros órgãos como baço, coração, osso, encéfalo e tecido subcutâneo. 0 desenvolvimento do cisto hidático no hospedeiro intermediário é lento e a maturidade é alcançada em 6-12 meses. No fígado e nos pulmões o cisto atinge $5-10 \mathrm{~cm}$. A cápsula do cisto compreende uma membrana externa laminada e um epitélio germinativo interno de onde, quando o desenvolvimento do cisto está quase completo, brotam cápsulas prolígeras cada uma delas contendo vários escólices. Muitas dessas cápsulas destacam-se e os escólices aparecem livres no líquido da hidátide. Isso é

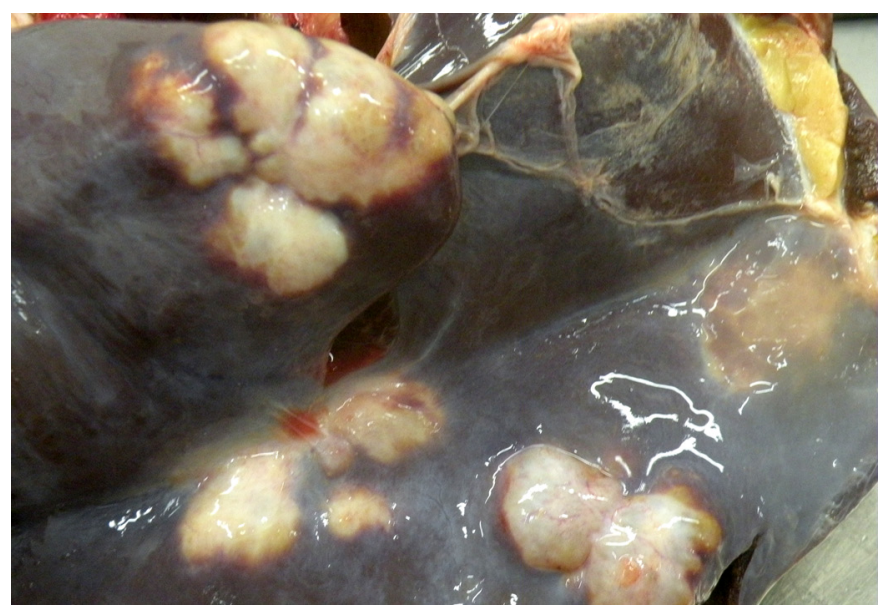

Fig.2. Múltiplos cistos hidáticos no fígado de um bovino.

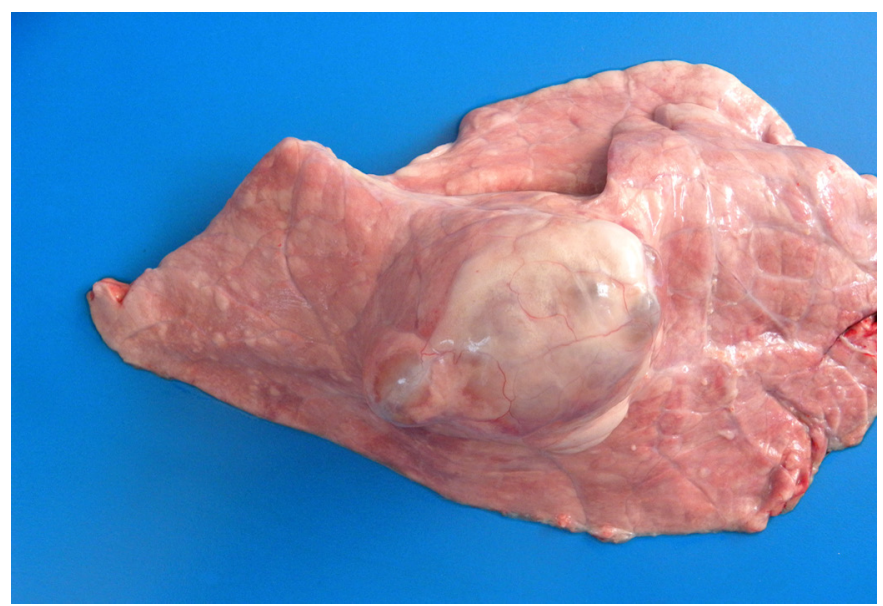

Fig.3. Cisto hidático solitário no pulmão de um bovino. 0 cisto é esférico túrgido e cheio de líquido.

comumente referido como "areia hidática". Algumas vezes cistos filhos são formados dentro do cisto materno ou externamente ao cisto, no tecido circunvizinho; neste último, caso eles se desprendam podem ser levados a outras partes do organismo para formar novos cistos hidáticos. Quando o hospedeiro definitivo ingere tecidos de hospedeiros intermediários contendo cistos viáveis, o ciclo recomeça (Fig.1).

Neste estudo, 17 cistos hidáticos (55\%) foram observados no fígado (Fig.2), oito (26\%) no pulmão (Fig.3), três (10\%) no coração (Fig.4), um no músculo masseter (3\%), um no osso esterno (Fig.5) e um no rim. Em um dos bovinos foram observados múltiplos cistos no fígado e pulmões concomitantemente. Na literatura é descrito que, em bovinos, cerca de $90 \%$ dos cistos hidáticos localizam-se no fígado (Barros 2011), e o restante é distribuído por outros órgãos, incluindo pulmão, coração, rim, baço e osso (Alldred \& Nisbet 1964, Taylor et al. 2007). A localização do cisto e sua morfologia não dependem somente de fatores do hospedeiro, mas também da cepa ou espécie de Echinococcus envolvida. Os cistos variam de tamanho e podem ser numerosos em um mesmo órgão. Em bovinos, os cistos têm $5-10 \mathrm{~cm}$ (Taylor et al. 2007) e são frequentemente múltiplos e uniloculares (Torgerson \& Budke 2003). Quando viáveis os cistos são preenchidos por um líquido transparente. A 

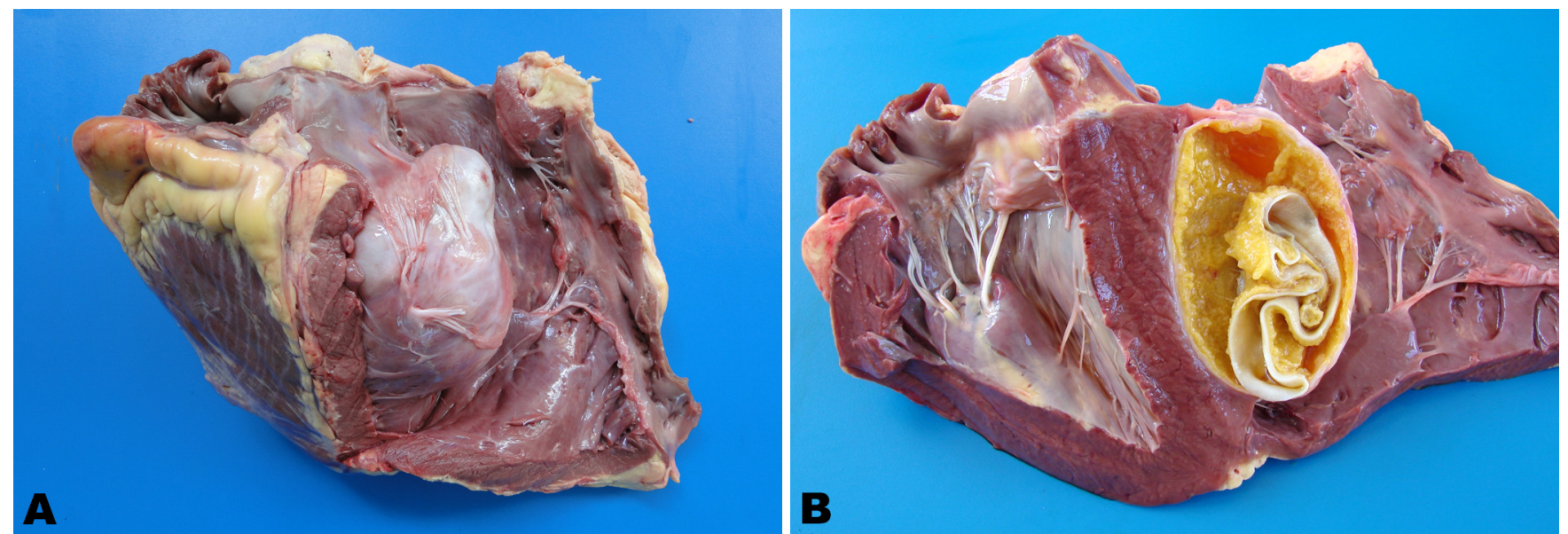

Fig.4. Cisto hidático no coração de um bovino. (A) Um cisto hidático de 14x8x6 cm localizado no septo interventricular projeta-se para o interior da câmara cardíaca do ventrículo direito. 0 cisto é recoberto por endocárdio e desloca as cúspides da valva tricúspide. Apesar disso, não foram relatados quaisquer sinais clínicos no exame antemortem deste bovino. (B) Corte transversal do cisto mostrado em A. A membrana laminada do cisto hidático está dobrada e separada da cápsula de tecido conjuntivo reacional do hospedeiro. Havia líquido amarelado (não mais representado) no espaço entre a cápsula do hospedeiro e a membrana laminada do parasita. 0 colapso da membrana laminada do parasita e o aspecto amarelado e rugoso observado na porção interna da cápsula do hospedeiro e na porção externa da membrana laminada do parasita indicam degeneração do cisto, o que é o achado mais comum em bovinos. Em estágios mais avançados haverá calcificação do cisto (ver Fig.8).
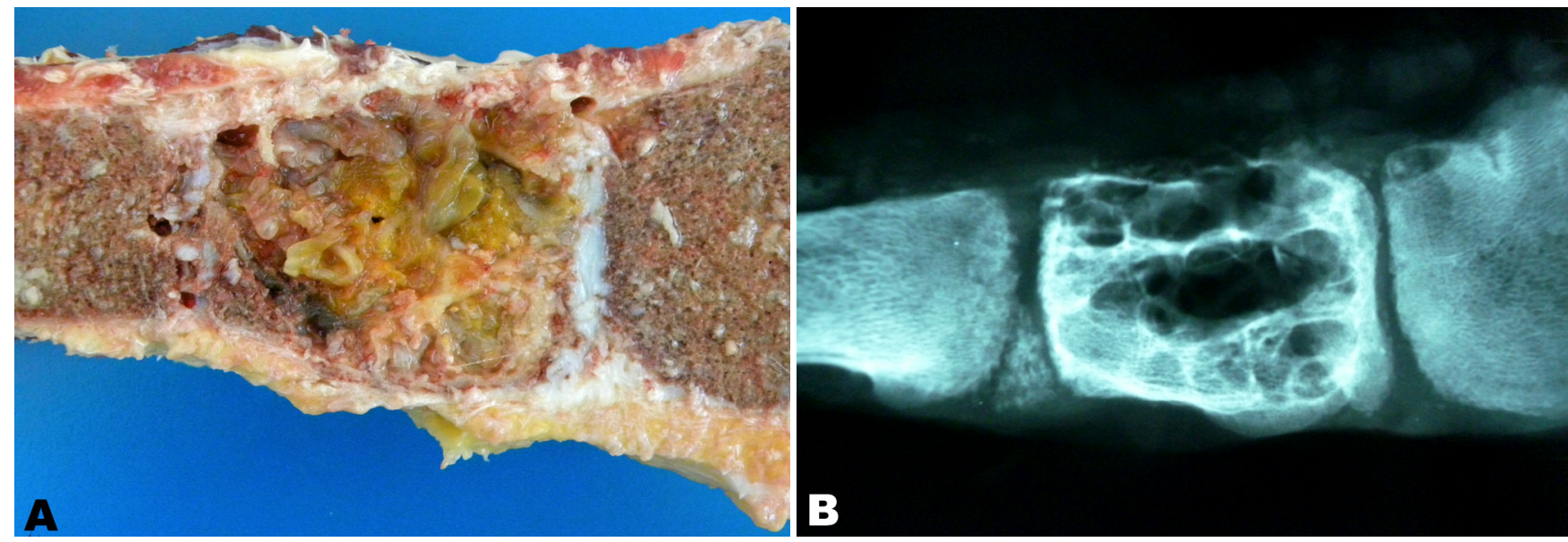

Fig.5. Hidatidose no osso esterno de um bovino. (A) A segunda esternébra está praticamente destruída formando uma lesão multivesicular (múltiplos cistos), dentro de cada um é observada a membrana laminada do cisto. (B) Aspecto radiográfico da lesão em A.

composição do fluido é uma mistura de moléculas derivadas do hospedeiro e do parasita. 0 tipo e a concentração das moléculas derivadas do parasita diferem entre cistos férteis e inférteis (Irabuena et al. 2000). Com o passar do tempo, o cisto hidático degenera e se torna inviável (Barros 2011); nesses casos, observa-se uma massa caseosa e mineralizada (Stalker \& Hayes 2007) no centro do cisto.

Acredita-se que hidátide primária no osso ocorra quando um escólice transportado pela circulação passa o filtro do fígado e pulmão e é levado pela circulação até o osso. Isso explica a raridade dessa condição óssea (Alldred \& Nisbet 1964). 0 crescimento no osso é lento. No osso é sugerido que a lesão assuma uma rara forma alveolar, no entanto o mais provável é que o crescimento lento e a presença de pequenos cistos sejam devidos à resistência do osso ao crescimento do parasita. 0 caso encontrado em nosso estudo afetava o esterno e praticamente destruía toda a segunda esternebra (Fig.5) formando uma lesão multivesicu- lar (múltiplos cistos), dentro de cada vesícula foi observada a membrana laminada do cisto.

Microscopicamente, os cistos hidáticos examinados neste estudo mostravam a seguinte morfologia (Fig.6), que é comparável ao que é descrito na literatura (Eberhard \& Alcaraz 2006, Taylor et al. 2007, Brown 2009, Barros 2011). Os componentes do cisto que pertencem ao hospedeiro consistiam de uma espessa cápsula mais externa de tecido fibrovascular infiltrada por células mononucleares e alguns eosinófilos e de uma camada inflamatória formada por macrófagos epitelioides, por vezes com células gigantes, algumas células mononucleares e alguns eosinófilos. Os componentes do cisto que pertencem ao parasita consistiam externamente de uma membrana hialina acelular laminada e uma delgada camada germinativa. A partir dessa última, e presas a ela por delicados pedículos, brotavam as cápsulas prolígeras contendo vários escólices.

Em bovinos, estima-se que $90 \%$ dos cistos sejam esté- 

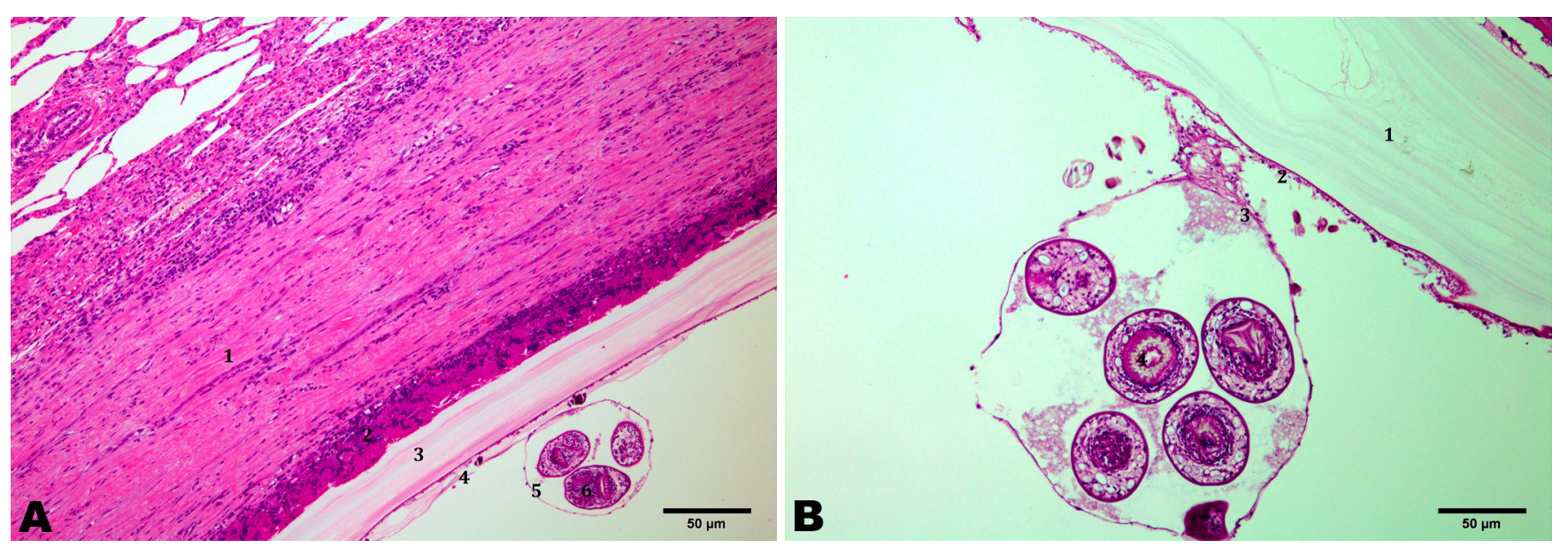

Fig.6. Aspecto histológico do cisto hidático em bovino. (A) Os componentes do cisto que pertencem ao hospedeiro consistem de uma espessa cápsula mais externa de tecido fibrovascular infiltrada por células mononucleares e alguns eosinófilos (1) e de uma camada inflamatória formada por macrófagos epitelioides por vezes com células gigantes, algumas célula mononucleares e alguns eosinófilos (2). Os componentes do cisto que pertencem ao parasita são (a contar da porção mais externa para o interior do cisto) uma membrana hialina acelular laminada (3) e uma delgada (4) camada germinativa (melhor observada em [2] na Figura 6B. A partir da cápsula germinativa, e presas a ela por delicados pedículos, brotam as cápsulas prolígeras (5). A cápsula prolígera mostrada nesta ilustração contém três protoescólices (6). HE, obj.20x. (B) Maior aumento da porção interna de um cisto hidático fértil mostrando apenas os componentes pertencentes ao parasita; a membrana hialina acelular lamina-

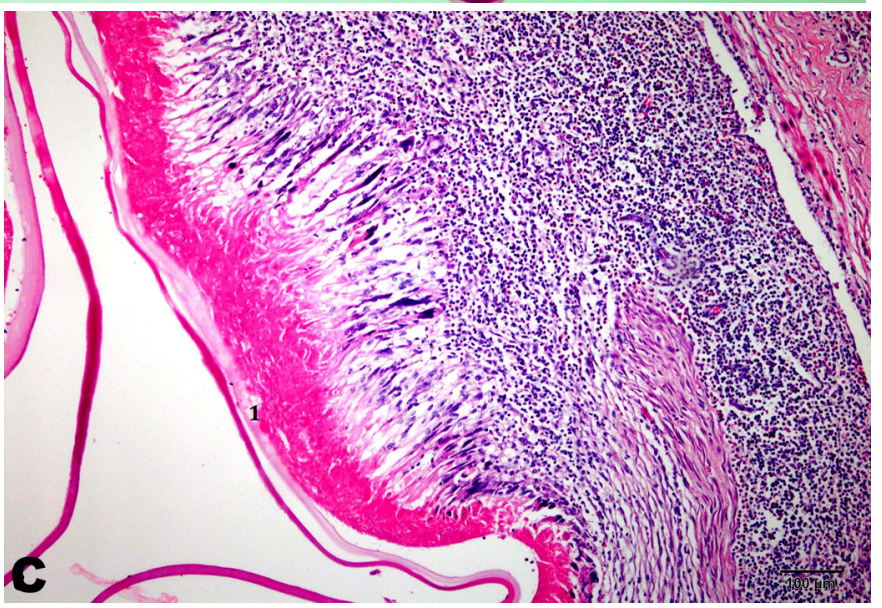
da (1), a camada germinativa (2), uma cápsula prolígera (3) contendo cinco protoescólices (4). Se essas cápsulas são rompidas os protoescólices podem ser liberados no líquido do cisto formando o que é chamado de "areia hidática". Se o cisto se rompe, os protoescólices podem ser liberados no tecido circunjacente propiciando a formação de cistos secundários. HE, obj.40x. (C) Aspecto histológico de cisto estéril. Há forte reação granulomatosa. Compare o aspecto da membrana laminar degenerada (1) com o aspecto da membrana viável do cisto mostrado em A e B. 0 epitélio germinativo é hialino e não contém núcleos e não há cápsulas prolígeras com protoescólices. HE, obj.20x.

reis (Wilson 2005); isso foi confirmado nesse levantamento, onde apenas três casos de hidatidose $(10 \%)$ observados microscopicamente possuíam todas as camadas constituintes do cisto, os demais casos apresentavam apenas a camada laminada (Fig.7) ou já estavam calcificados (Fig.8). Nos cistos hidáticos inférteis, a membrana laminada é a única característica diagnóstica disponível (Eberhard \& Alcaraz 2006). Qualquer fator que ameace a vida do cisto, como a entrada de bile, conduzirá à formação de cistos filhos dentro do cisto original (Wilson 2005), originando os cistos multivesiculares. Em estudo (Kul \& Yildiz 2010) verificou-se um total de quatro cistos multivesiculares em 1.255 bovinos abatidos. Em nosso estudo, dos 30 casos de cistos hidáticos, quatro apresentaram-se como multivesiculares. Em raros casos, E. granulosus produz cistos multivesiculares, os que possuem morfologia similar a cistos alveolares (Kul \& Yildiz 2010), mas devem ser diferenciados desses últimos. Cistos filhos exógenos são formados por brotamentos externos devido ao escape de pedaços da camada germinativa (Wilson 2005), podendo, ocasionalmente, se soltar e ser carreados para outras partes do corpo para formar novas hidátides (Urquhart et al. 1996, Taylor et. al. 2007, Brown 2009).
Pelo baixo valor comercial dos ovinos em comparação a bovinos, essa espécie é frequentemente abatida em casa, tornando mais fácil o acesso de cães às vísceras infectadas com cisto hidático, em seguida esses cães passam a infectar com ovos as fazendas de bovinos (Scala et al. 2004, Cringoli et al. 2007). Isso explica a hidatidose ser a doença parasitária mais prevalente em nosso levantamento, uma vez que todos os casos dessa parasitose foram provenientes do Rio Grande do Sul, que possui o maior rebanho ovino do país (IBGE 2006), sendo que a região sudoeste do Estado é aquela com a maior densidade ovina (SEAPA 2010) e de onde grande parte dos bovinos com hidatidose deste estudo provinham.

A repercussão da presença de cistos hidáticos na saúde em bovinos é pouca ou nula, a não ser que o cisto se instale numa porção vital de um órgão, o que é muito raro (Taylor et al. 2007, Brown 2009). Grande número de cistos no fígado, pulmão, baço e inclusive coração são tolerados pelo hospedeiro sem apresentação de sinais clínicos. 0 cestoide adulto não é patogênico e milhares podem ser encontrados no hospedeiro definitivo, sem provocar sinais clínicos. No entanto, quando os cistos ocorrem no fígado e pulmão 

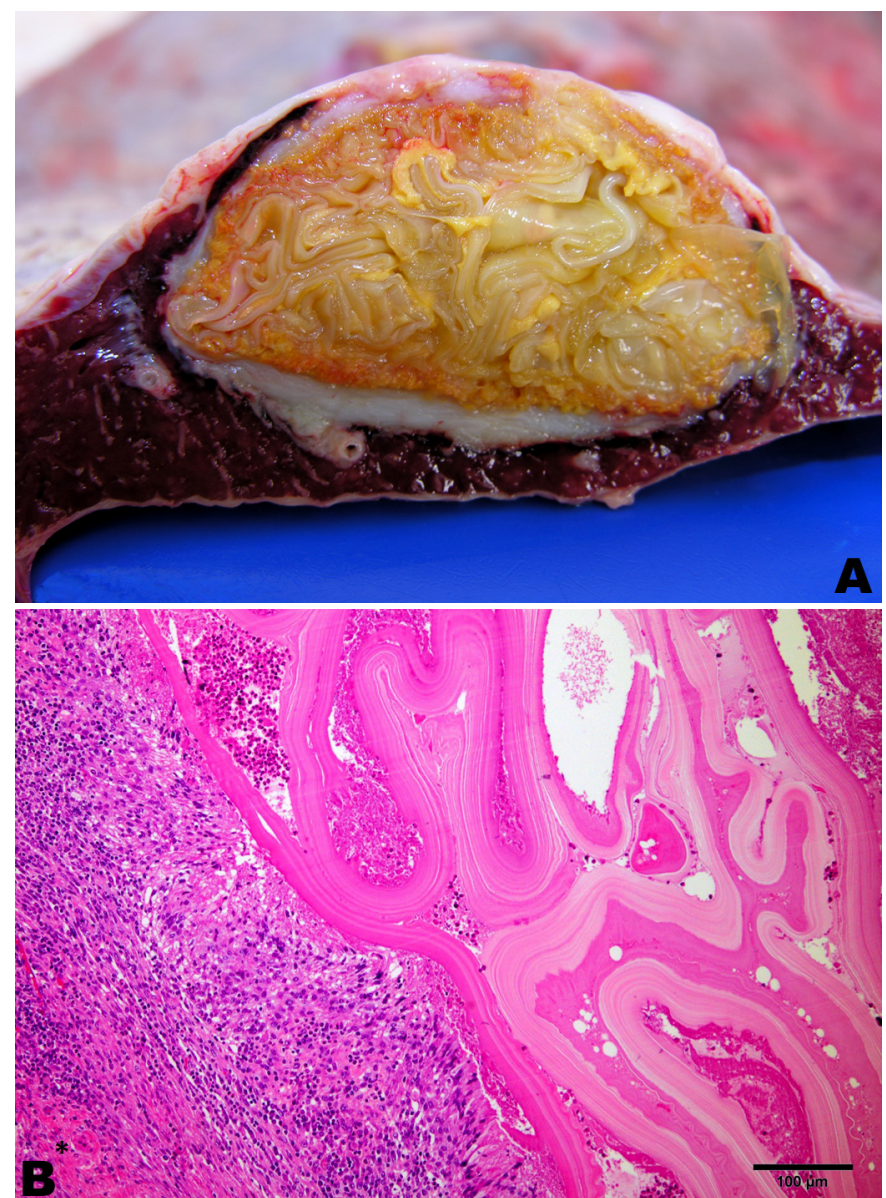

Fig.7. Cisto hidático degenerado no baço de um bovino. (A) 0 colapso da membrana laminada do parasita forma um emaranhado de membranas dobradas dentro da cavidade do cisto. 0 aspecto amarelado indica degeneração incipiente. A maior parte dos cistos hidáticos é estéril. (B) Aspecto histológico da lesão. Do lado direito observa-se o emaranhado da membrana laminada do parasita, com sinais de degeneração e infiltração por células inflamatórias. Não se observa a membrana germinativa ou escólices. À esquerda do emaranhado de membrana laminada do parasita há uma reação inflamatória do hospedeiro constituída principalmente por macrófagos epitelioides, células mononucleares e alguns eosinófilos. Circundando tudo isso aparece ainda um pedaço da cápsula conjuntiva do hospedeiro (asterisco). HE, obj.40x.

de seres humanos, geralmente apresentam significado patogênico (Taylor et al. 2007). Humanos são hospedeiros acidentais; contaminando-se acidentalmente quando as oncosferas são ingeridas da pelagem de cães ou transferidas quando os cães lambem pessoas, através da ingestão de vegetais ou outros alimentos contaminados com fezes de cães (Grist 2008). Na equinococose humana os pacientes podem demonstrar sintomas devido à compressão do cisto em estruturas circunjacentes ou pela liberação de material antigênico de ruptura de cisto com desenvolvimento de reações imunológicas secundárias (Morar \& Feldman 2003). Embora seja amplamente aceito que humanos (que são hospedeiros intermediários ocasionais) adquirem a doença apenas do hospedeiro definitivo (no caso, o cão) e não de outro hospedeiro intermediário (por ex., ovinos, bovi-

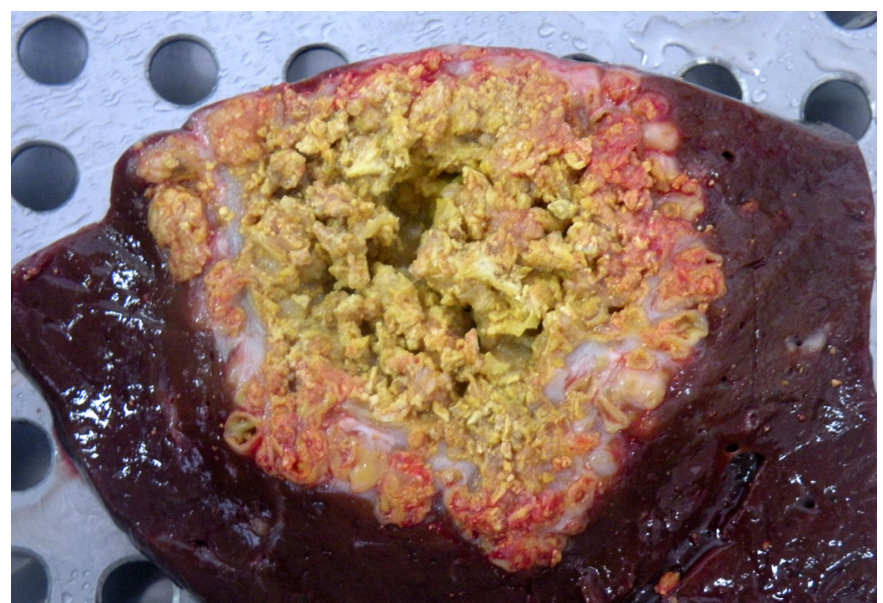

Fig.8. Cisto hidático degenerado no fígado de um bovino. A estrutura interna do cisto colapsou e as membranas degeneraram e tornaram-se caseosas e calcificadas. Nessa fase, a lesão pode ser confundida com tuberculose devido ao aspecto caseoso e à calcificação. Um exame cuidadoso pode revelar fragmentos remanescentes da cápsula laminada, o que facilita o diagnóstico diferencial. Cistos hidáticos estéreis frequentemente se desenvolvem em bovinos tornando o diagnóstico difícil.

nos) pudemos encontrar dois relatos na literatura em que isso é relatado. Em um deles (Bassyouni \& Maher 1978) uma paciente de 30 anos adquiriu um cisto contaminado por Staphylococcus nas tonsilas pelo hábito de consumir fígado de ovelha cru. Embora esse episódio de implantação direta dos protoescólices nas tonsilas não tenha sido definitivamente comprovado, já foi sugerido que o hábito de ingerir fígado cru pode levar à implantação direta dos protoescólices na cripta das tonsilas (Beard 1976). A teoria da implantação direta é apoiada em um caso de um trabalhador de laboratório que desenvolveu um pequeno cisto no saco conjuntival (confirmado histologicamente como cisto hidático) após alguns meses de ter o conteúdo de um cisto acidentalmente espirrado em seus olhos após ruptura acidental no trabalho de laboratório (Beard 1976).

\section{Fasciolose}

A parasitose por Fasciola hepatica, um trematoide (filo Plathyhelminthes, classe Trematoda, subclasse Digenea, família Fasciolidae), é denominada fasciolose. 0 parasita tem forma de folha com aproximadamente $2,5 \mathrm{~cm}$ de comprimento. Afeta preferencialmente o fígado de bovinos, ovinos (Brown et al. 2007, Taylor et al. 2007, Brown 2009), mas infecções patentes podem se desenvolver em outros animais domésticos e selvagens e em seres humanos (Stalker \& Hayes 2007, Barros 2011). A doença é também conhecida como distomíase. Fasciola hepatica é hermafrodita e apenas um exemplar é necessário para estabelecer a infecção, uma vez que um trematoide adulto pode produzir 20.000 ovos por dia (Taylor et al. 2007). 0 ciclo de vida de F. hepatica (Fig.9) necessita de um caramujo (Lymnaea spp.) como hospedeiro intermediário (Mattos et al. 1997) e é descrito como se segue (Stalker \& Hayes 2007). Os ovos são eliminados com a bile, e posteriormente com as fezes. Quando no pasto, em condições adequadas de calor e umidade, os 


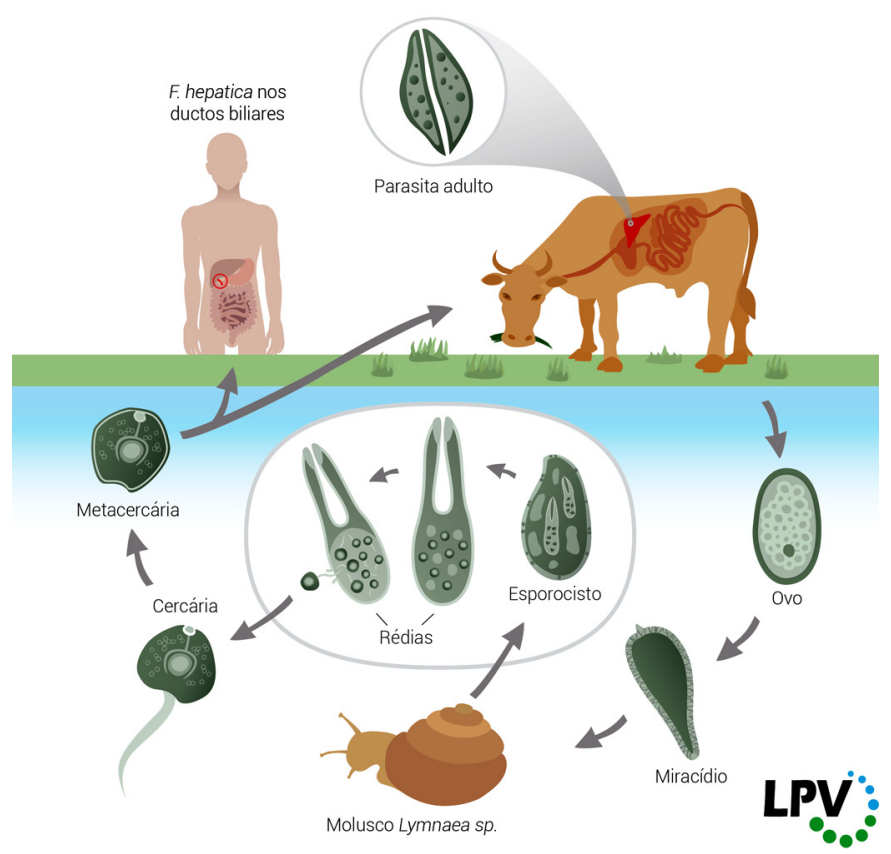

Fig.9. Ciclo de vida de Fasciola hepatica. Os ovos são eliminados com a bile, subsequentemente nas fezes e eclodem produzindo um miracídio que sobrevive apenas em ambientes úmidos. 0 miracídio penetra ativamente no hospedeiro intermediário (caramujo do gênero Lymnaea). Dentro do caramujo cada miracídio se desenvolve em um esporocisto. Cada esporocisto dá origem a 5-8 rédias que, por sua vez, dão origem a rédias filhas e cercárias. Cercárias abandonam o caramujo e se encistam nas lâminas de vegetais, logo abaixo do nível da água, tornando-se metacercárias. 0 hospedeiro final (ruminante) ingere as metacercárias junto com as plantas. Pessoas e outros mamíferos domésticos e silvestres podem também se infectar. As metacercárias ingeridas desfazem o cisto no duodeno do hospedeiro definitivo e penetram na parede intestinal migram através do celoma e penetram na cápsula do fígado e migram pelo parênquima hepático até atingir os ductos hepáticos.

ovos eclodem produzindo um miracídio (forma larval) em aproximadamente 10 dias. 0 miracídio pode sobreviver apenas em ambientes úmidos, o que explica o fato da doença ocorrer em regiões planas e alagadiças. 0 miracídio é móvel e penetra ativamente no hospedeiro intermediário que é um caramujo aquático. Diferentes caramujos servem esse propósito em diferentes partes do mundo, mas todos eles pertencem ao gênero Lymnaea. Dentro do caramujo cada miracídio se desenvolve em um esporocisto mãe que se reproduz dando origem a organismos de segunda geração, as rédias. Cada esporocisto dá origem a 5-8 rédias que, por sua vez, dão origem a rédias filhas e cercárias. Cercárias abandonam o caramujo em 4-7 semanas após a penetração dos miracídios e acomodam-se nas lâminas de gramíneas ou outras plantas, logo abaixo do nível da água. As cercárias se encistam, tornando-se metacercárias e permanecem nas plantas ou submergem ao fundo da água. Sob as condições favoráveis, esses eventos (ovos até cercárias encistadas) levam 1-2 meses. 0 hospedeiro final (ruminante) ingere as metacercárias junto com as plantas. Bovinos e outros animais que caminham na água em que bebem podem, com o movimento das patas na água, fazer com que as metacercárias que repousam no fundo emerjam para a superfície propiciando sua ingestão pelos animais que bebem a água contaminada. As metacercárias ingeridas desfazem o cisto (excistam) no duodeno do hospedeiro definitivo e penetram na parede intestinal. Vinte e quatro horas após a infecção, a maioria dos trematoides imaturos estão na cavidade abdominal e após 4-6 dias a maioria penetrou na cápsula hepática e migrou através do parênquima. Embora algumas formas imaturas do trematoide possam chegar ao fígado por via hematogênica, a via usual é a transcelômica (através da cavidade abdominal) e as metacercárias penetram pela cápsula e migram pelo parênquima hepático até os ductos biliares. A migração pelo parênquima hepático dura 5-6 semanas. Cerca de 7 semanas após a infecção, os trematoides imaturos alcançam os ductos biliares onde atingem a maturidade sexual em 2-3 meses. A partir desse momento, os ovos são encontrados na bile e, subsequentemente, nas fezes. Alguns trematoides podem penetrar acidentalmente as veias hepáticas e daí atingirem a circulação sistêmica e localizar-se em sítios incomuns, particularmente nos pulmões de bovinos.

Dos 21 casos de fasciolose observados neste estudo, 18 estavam localizados no fígado e três no pulmão. Os casos de fasciolose hepática deste levantamento enquadravam-se na forma crônica da doença, que é a forma mais comum em bovinos (Costa 2010, Barros 2011). Caracteristicamente, observou-se espessamento por fibrose (Fig.10) e calcificação do revestimento interno dos ductos biliares. No interior dos ductos afetados havia exsudato marrom-escuro e viscoso, formado por flocos de bile, pus, células epiteliais de revestimento ductal descamadas, fragmentos e ovos de trematoides. Exemplares de $F$. hepatica podiam ser observados em meio ao exsudato em alguns fígados (Fig.11). Frequentemente o lobo esquerdo estava atrofiado (Fig.12). Diferentes tipos de fibrose são descritas em lesões causadas por $F$. hepatica (Urquhartet al. 1996): (1) cicatriz pós-necrótica, observada no lobo esquerdo e associada à cura dos tratos fistulosos. Essa cicatriz é principalmente devida à fibrose passiva, isto é, prevalência do tecido fibro-

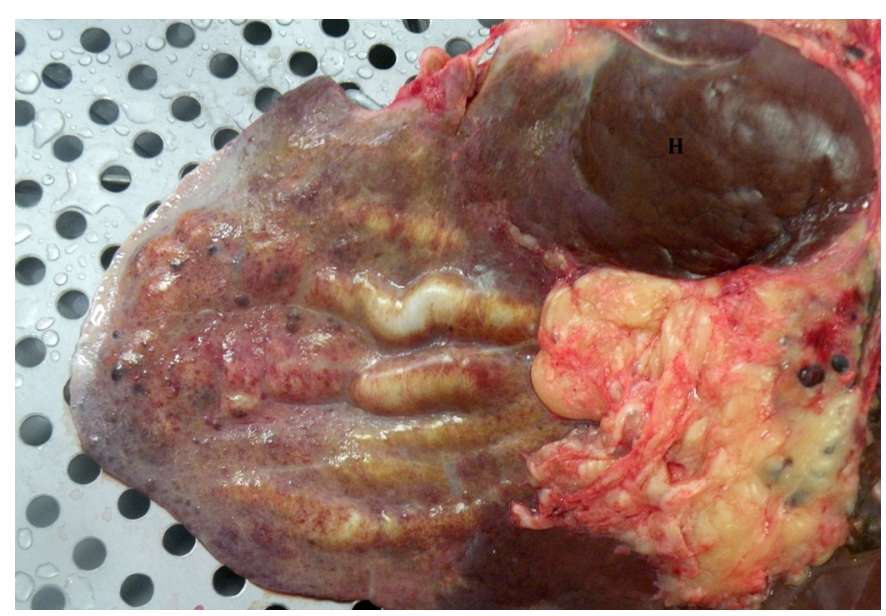

Fig.10. Fasciolose hepática em bovino. Os ductos biliares do lobo esquerdo do fígado estão acentualmente espessados. Há atrofia do lobo esquerdo e hiperplasia $(\mathrm{H})$ da porção visível do lobo direito. 

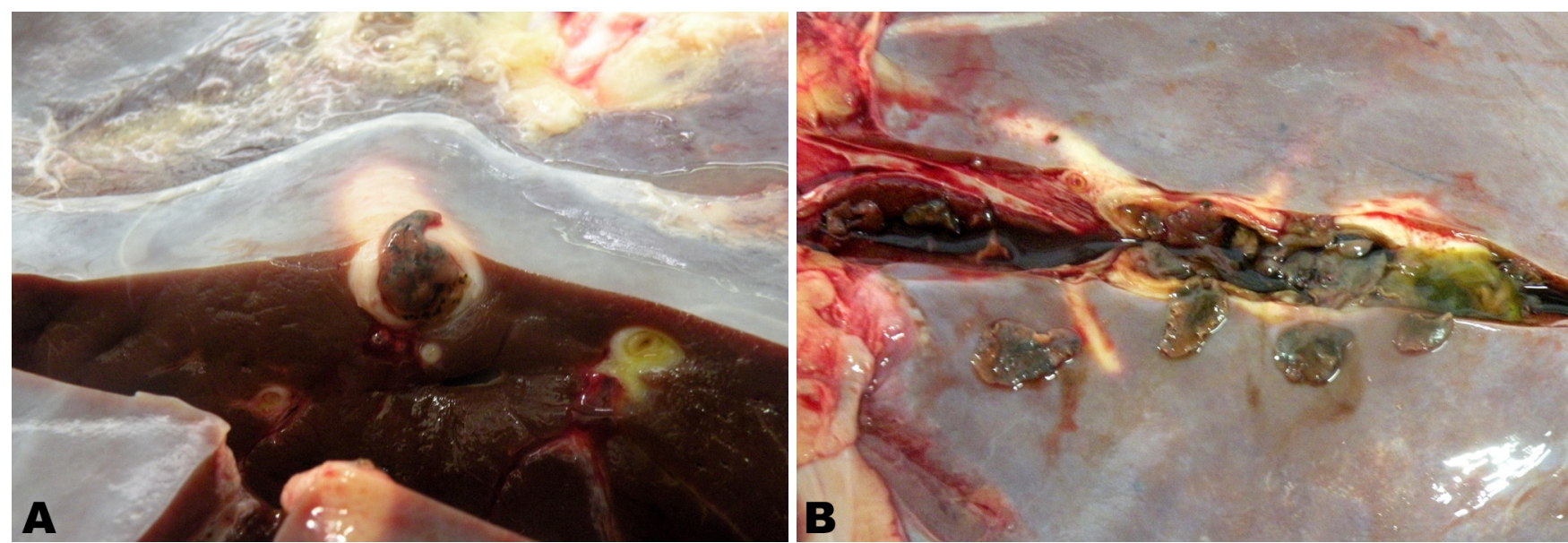

Fig.11. Fasciolose hepática em bovino. (A) Um parasita adulto projeta-se do interior de um ducto espessado por tecido fibroso e infiltrado inflamatório. (B) Exemplares de Fasciola hepatica podem ser observados em meio ao exsudato na luz dos ductos. 0 revestimento ductal está calcificado.

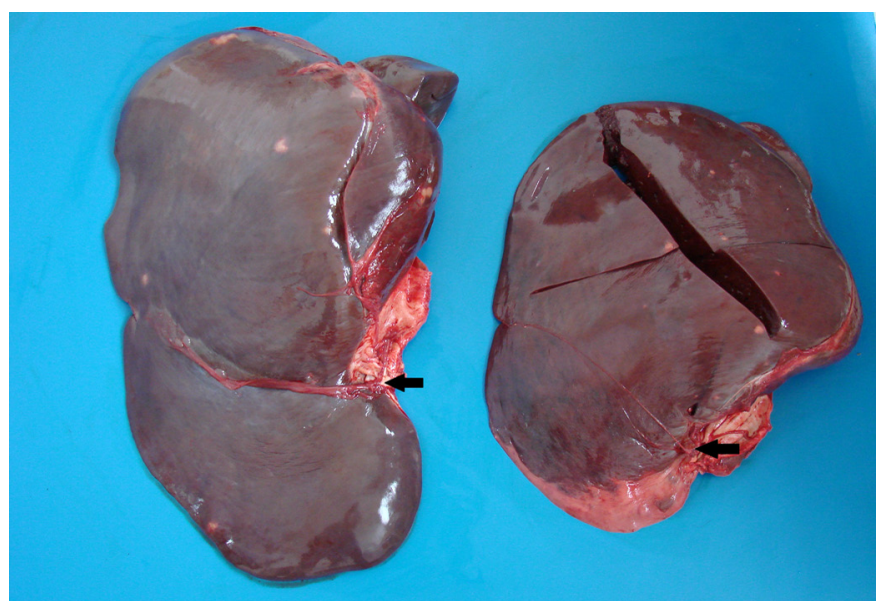

Fig.12. Atrofia do lobo esquerdo na fasciolose hepática em bovino. 0 lobo esquerdo do fígado à esquerda tem o tamanho normal, para comparação com o fígado da direita que tem o lobo esquerdo acentuadamente atrofiado secundariamente à infestação por Fasciola hepatica. As setas mostram os limites entre os lobos esquerdo e direito de cada fígado. Os pequenos pontos brancos multifocais em ambos os figados são pequenos cistos hidáticos.

so, devido à perda de hepatócitos; (2) a fibrose isquêmica, decorrente da sequência de infartos causados por danos e trombose nos grandes vasos; e (3) fibrose peribiliar, que se desenvolve quando as larvas atingem os ductos biliares.

Microscopicamente havia colângio-hepatite acentuada (Fig.13) semelhante ao que já foi descrito na literatura (Marcoset al. 2007). Grande parte do parênquima hepático ao redor dos ductos era substituído por tecido conjuntivo fibroso, o qual estabelece pontes entre os trajetos migratórios e o tecido normal, o que provoca a subdivisão do parênquima em lóbulos irregulares com infiltrado inflamatório constituído por linfócitos, plasmócitos, macrófagos, eosinófilos e menor número de neutrófilos, os quais foram observados nas tríades portais e em áreas aleatórias do parênquima. A colangite ocorre devido a presença dos parasitas adultos nos ductos biliares: o epitélio torna-se hiperplásico nas proximidades e à distância da $F$. hepati$c a$ e muitos eosinófilos, bem como células mononucleares infiltram-se na lâmina própria (Tanimoto et al. 1998). As alterações histopatológicas nos ductos biliares durante as fases iniciais da infecção ocorrem muito antes dos parasitas os penetrarem e são caracterizadas pela hiperplasia do epitélio dos ductos, com o decorrer do tempo há deposição de cálcio que leva a incrustações mais ou menos visíveis (Stalker \& Hayes 2007). Estudos da infecção por F. hepatica em ratos (Campbell et al. 1981), sugeriram que a prolina, substância produzida pelo parasita, poderia ser um estímulo para induzir a hiperplasia nos ductos biliares. Há também evidências de que a síntese e a excreção de prolina por F. hepatica pode ser responsável, ao menos em parte, pela anemia que muitas vezes acompanha a infecção com esse trematoide (Isseroffet al. 1979). Parasitas adultos ocasionalmente foram observados em cortes histológicos no interior dos ductos (Fig.13), sendo caracterizados por um tegumento externo e ausência de celoma. 0 tegumento dos trematoides é um epitélio sincicial contínuo e organizado que forma uma membrana espessa aparentemente multilamelada (Eberhard \& Alcaraz 2006). Um elevado número de fascíolas pode levar a obstrução dos ductos biliares, causando estase biliar e, consequentemente, inflamação do epitélio das vias biliares e formação de abscessos (Teichmannet al. 2000). Frequentemente foi observado pigmento marrom a preto granular nas proximidades das lesões, esse pigmento está presente no ceco de trematoides, sendo associado à destruição das células sanguíneas (Gardiner \& Poynton 1999).

Os casos de fasciolose pulmonar eram caracterizados por nódulos ou cistos de diferentes tamanhos, rodeados por tecido conjuntivo fibroso (Fig.14). Esses nódulos variavam de um a vários centímetros de diâmetro e consistiam em abscessos situados na extremidade de brônquios e contendo líquido viscoso, com aspecto achocolatado e parcialmente coagulado em meio ao qual podiam se observar os parasitas, embora seja relatado que no pulmão os parasitas sejam menores e mais difíceis de visualizar (Stalker \& 


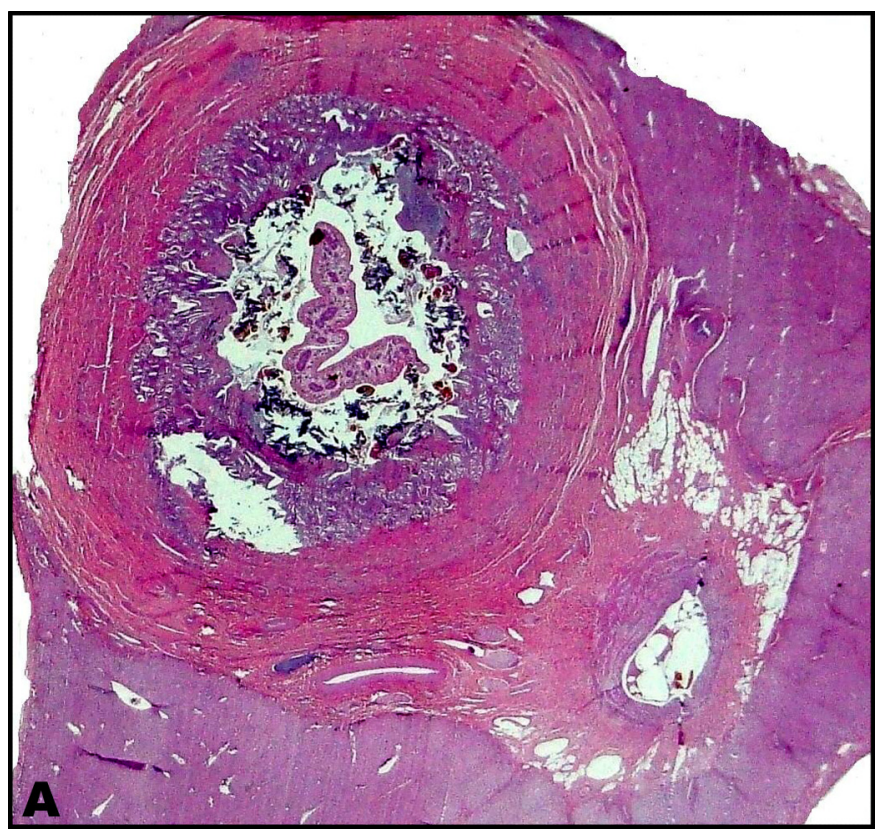

Hayes 2007). Na microscopia as extremidades dos brônquios estavam repletas de exsudato com muitos eosinófilos e neutrófilos degenerados. Os brônquios tinham as paredes espessadas e muitas vezes continham exemplares dos trematoides (Fig.15).

A fasciolose em bovinos causa grandes prejuízos econômicos, tanto pela condenação de fígados em abatedouros quanto pela pela redução na produção e qualidade do leite, do ganho de peso, atraso no crescimento, diminuição

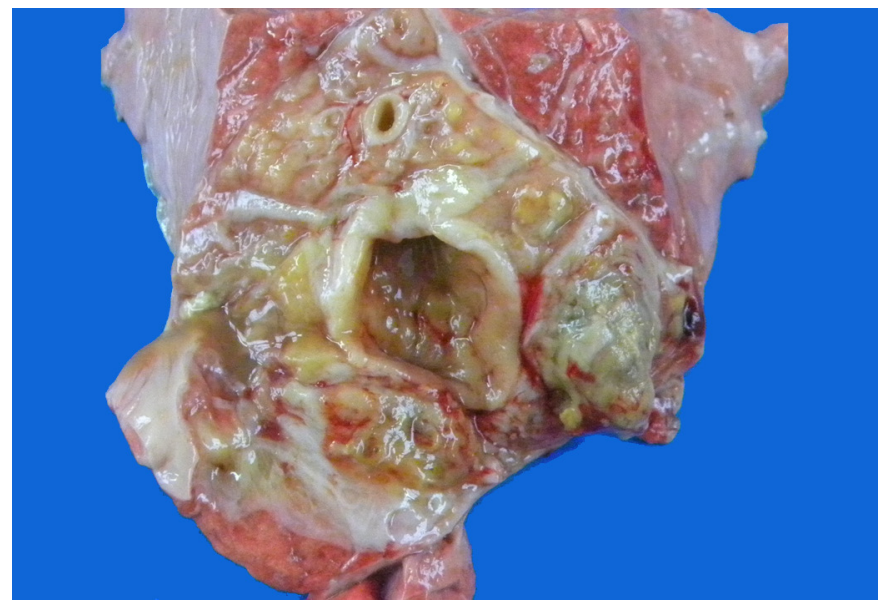

Fig.14. Fasciolose pulmonar em bovino. Durante o desenvolvimento do ciclo, alguns trematoides penetram acidentalmente as veias hepáticas e daí atingem a circulação sistêmica e localizam-se em sítios incomuns, particularmente nos pulmões de bovinos. Na ilustração vemos um aspecto característico da lesão que consistem em cistos de diferentes tamanhos, rodeados por tecido conjuntivo fibroso. Esses nódulos variam de um a vários centímetros de diâmetro e são abscessos de paredes finas situados na extremidade de brônquios e contêm líquido viscoso, com aspecto achocolatado e parcialmente coagulado em meio ao qual podem se observar os parasitas. No espécime da ilustração o conteúdo do cisto foi drenado antes da tomada da foto.

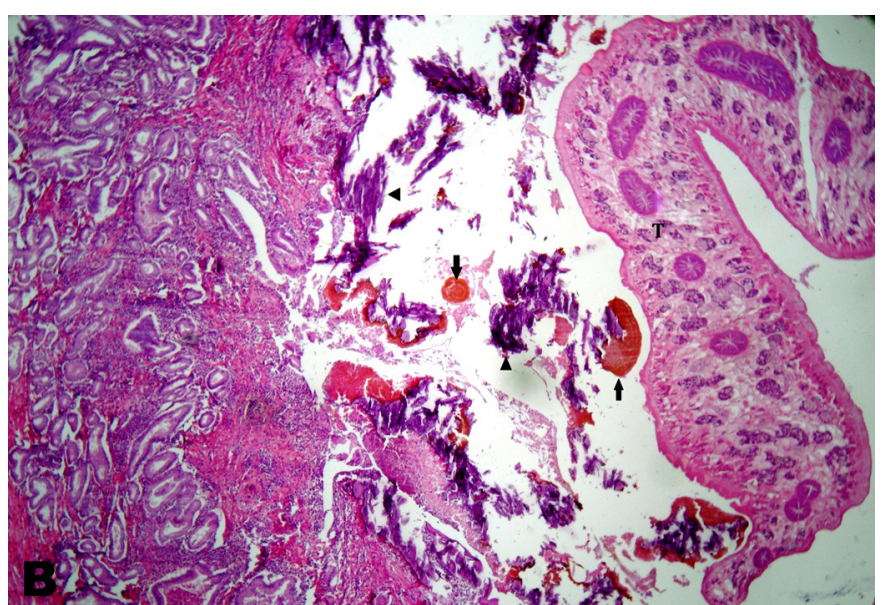

Fig.13. Histopatologia da lesão característica da fasciolose bovina. (A) 0 ducto afetado mostra uma espessa cápsula de tecido conjuntivo e infiltração por eosinófilos e células mononucleares. Há hiperplasia acentuada do epitélio ductal e um exemplar adulto de F. hepatica na luz do ducto. HE, obj.20x. (B) Maior aumento de lesão semelhante da mostrada em A. À esquerda aparece o epitélio hiperplásico do ducto afetado. Na luz do ducto há um trematoide (T). Observe a ausência de celoma no parasita. Pode-se ver também, pigmento do trematoide (setas) exsudado e mineralização (cabeças de setas). Esses constituintes formam o material viscoso e marrom observado macroscopicamente. HE, obj.40x.

da fertilidade e custos no tratamento da doença ou das infecções secundárias (Cunha et al. 2007). Em 2011 e 2012 o número de fígados condenados por fasciolose no Estado do Rio Grande do Sul (RS) foi de 126.794 e 101.849, respectivamente (Brasil 2011, 2012). Em nosso levantamento, a fasciolose está entre as doenças parasitárias mais frequentes, isso se deve a grande parcela das amostras hepáticas ter sido coletada de bovinos provenientes de municípios situados na fronteira do Rio Grande do Sul com o Uruguai, área reconhecidamente endêmica (Müller 2007).

\section{Cisticercose}

A terceira doença parasitária mais prevalente neste levantamento foi a cisticercose, porém esses dados podem não condizer com a realidade, uma vez que a inspeção de rotina detecta apenas $27 \%$ dos animais positivos (Walther \& Koske 1980). Os motivos para muitos casos passarem despercebidos são a infecção moderada e a restrição em termos comerciais, pois não é permitida a incisão em carnes nobres, o que não exclui a possibilidade de estarem afetadas. Outros fatores envolvidos que podem limitar a eficiência diagnóstica da cisticercose são as características do estabelecimento, como por exemplo, a má iluminação e o excesso de trabalho e a pouca experiência do pessoal envolvido na inspeção (Pereira et al. 2006).

0 bovino, hospedeiro intermediário, ingere os ovos deTaenia saginata eliminados pelo hospedeiro definitivo, o homem (Fig.16). Os embriões penetram na parede intestinal e pela circulação sanguínea são carreados para várias partes do corpo do animal, onde se desenvolverão os cistos (Wilson 2005). Há grande disparidade na literatura quanto aos locais de predileção dos cistos de Cysticercus bovis, porém, para a maioria dos autores, os metacestoides são 

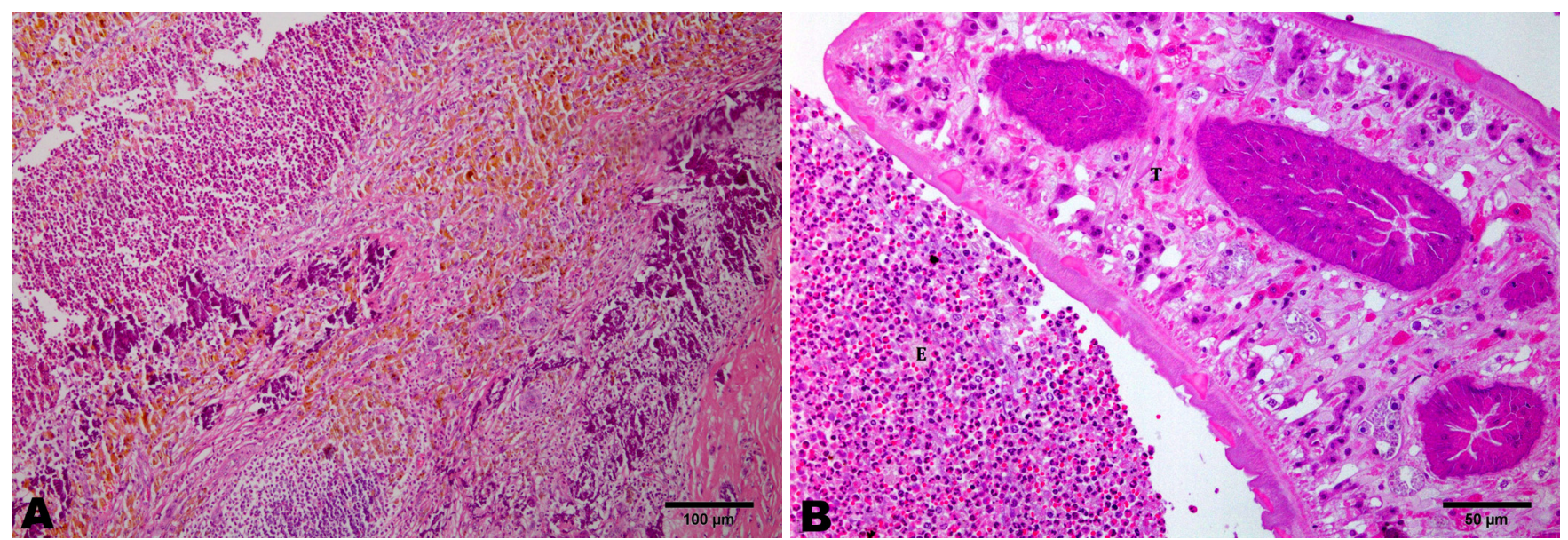

Fig.15. Histopatologia da lesão pulmonar causada por Fasciola hepática.(A) 0 brônquio afetado mostra uma espessa cápsula de tecido conjuntivo parcialmente calcificada e carregada de pigmento amarelado. Na luz há abundante exsudato polimorfonuclearneutrofílico e eosinofílico. HE, obj.20x. (B) Na luz do brônquio há um trematoide (T) em meio ao exsudato (E). HE, obj.40x.

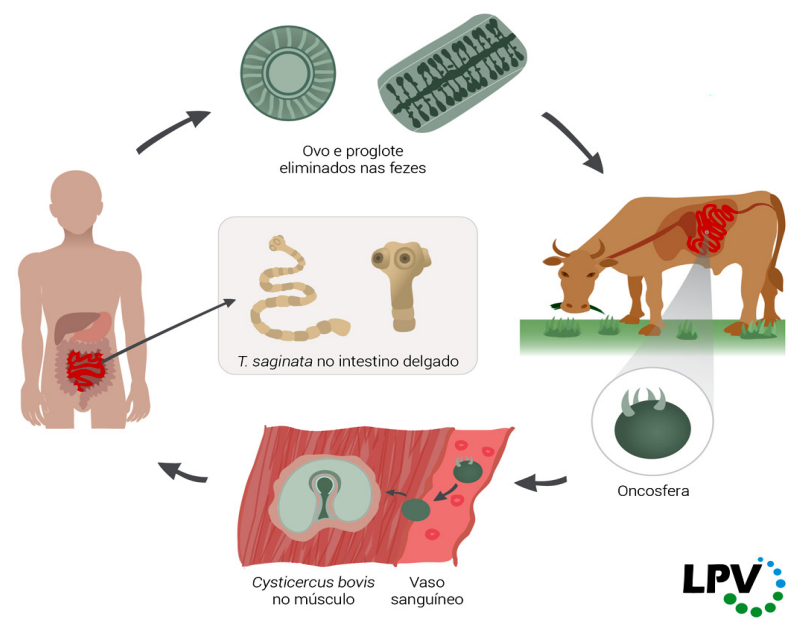

Fig.16. Ciclo de vida de Taenia saginata e de seu metacestoide, Cysticercus bovis. Uma pessoa infectada elimina milhões de ovos por dia, livres nas fezes ou em proglotes. Cada proglote contém cerca de 250.000 ovos. Os ovos podem sobreviver na pastagem por vários meses. Após a ingestão por um bovino suscetível (o hospedeiro intermediário), a oncosfera segue pela circulação sanguínea até o músculo estriado (esquelético ou cardíaco) onde se desenvolve em cisticerco (C. bovis) que é uma vesícula translúcida de cerca de $1 \mathrm{~cm}$ de comprimento (ver Fig.17) através da qual pode se ver um escólice. Cistos maturam de semanas a anos. Quando degeneram e morrem os cistos são substituídos por material caseoso e que pode calcificar tornando-se um pequeno foco calcário que se esfarela ao corte. Tanto os cistos vivos como os calcificados podem ser encontrados na mesma carcaça. Seres humanos tornam-se infectados ingerindo carne crua ou mal assada ou cozida. Período pré-patente é de 2-3 meses.

encontrados principalmente nos músculos mais irrigados, notadamente músculos mastigatórios e coração (Walther \& Koske 1980, Santos 2002, Costa et al. 2012), como demonstrado em nosso estudo (66\% dos casos). Essas divergências sobre a distribuição dos cisticercos nos diferentes sítios anatômicos pode ser decorrente de diversos fatores, como estudos realizados com populações grandes, porém de áreas geográficas diferentes, a habilidade e critério do inspetor e a não padronização das técnicas, uma vez que o exame do fígado, esôfago, diafragma e seus pilares não fazem parte da rotina de inspeção à procura de cisticercos na maioria dos matadouros, pois não constam nas exigências regulamentares (Souza et al. 2007, Costa et al. 2012).

A quantidade de cisticercos mortos (87\%) foi maior que a de vivos $(13 \%)$, sendo os dois casos de cisticercose viva observados no masseter, que é o local onde predominam metacestoides vivos, já o coração é o sítio anatômico em que os cisticercos calcificam mais rapidamente (Moreira et al. 2002). 0 maior número de cisticercos mortos está em consonância com os relatos da literatura (Santos et al. 2003, , Souza et al. 2007, Costa et al. 2012). A longevidade do $C$. bovis depende do tipo de tecido invadido e não é uniforme no mesmo animal (Pawlowski \& Schultz 1972), uma vez que pode ocorrer caseificação retardada ou a infecção pode ser adquirida em diferentes ocasiões na mesma pastagem (Grist 2008).

Não há dificuldade para o diagnóstico macroscópico de cisticercose bovina. 0 cisto parasitário possui cerca de $1 \mathrm{~cm}$ de diâmetro, é branco acinzentado (Fig.17) e preenchido por líquido em meio ao qual um escólex é usualmente visível (Urquhart et al. 1996). Contudo esse diagnóstico pode ser dificultado nos casos em que os cisticercos estejam mortos, ou seja, em lesões abscedadas e mineralizadas (Santos 1984), que nesse trabalho foram caracterizadas por nódulos firmes, amarelos, algumas vezes apresentando material granular no centro.

0 exame microscópico desses cisticercos degenerados nos diferentes sítios anatômicos revelou granulomas constituídos por um centro necrótico, frequentemente mineralizado, circundado por intensa reação inflamatória, composta por histiócitos dispostos em paliçada, ocasionalmente células gigantes multinucleadas, linfócitos, plasmócitos e eosinófilos (Fig. 8). Externamente havia proliferação de tecido conjuntivo fibroso. Em alguns casos, observaram-se estruturas redondas a ovais basofílicas ou anfofílicas no centro dos granulomas, representando restos parasitários (corpúsculos calcáreos). Os corpúsculos calcáreos são uma característica diagnóstica chave, já que são exclusivos 

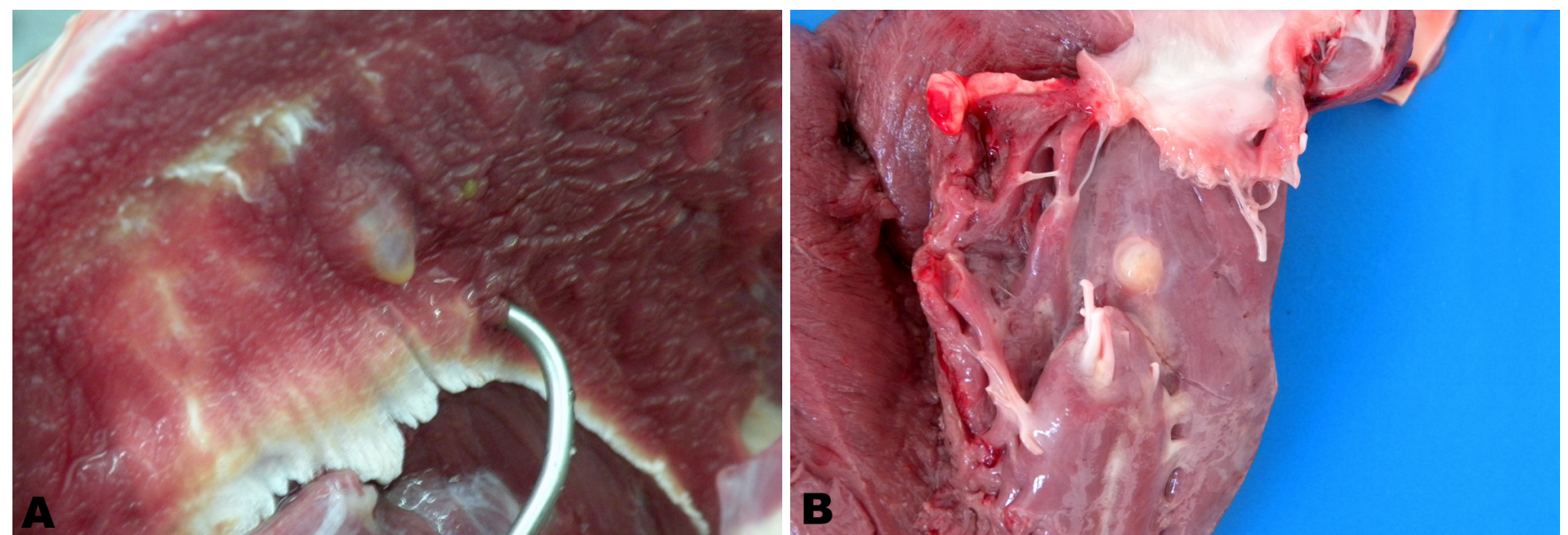

Fig.17. Locais frequentes de localização da cisticercose bovina (Cysticercus bovis). (A) Músculo masseter. (B) Coração. Em ambos os locais aparecem cistos viáveis, caracterizados por vesículas translúcidas de cerca de $1 \mathrm{~cm}$ de comprimento. Ao exame cuidadoso dessas vesículas pode-se ver um único escólice no interior do cisto.

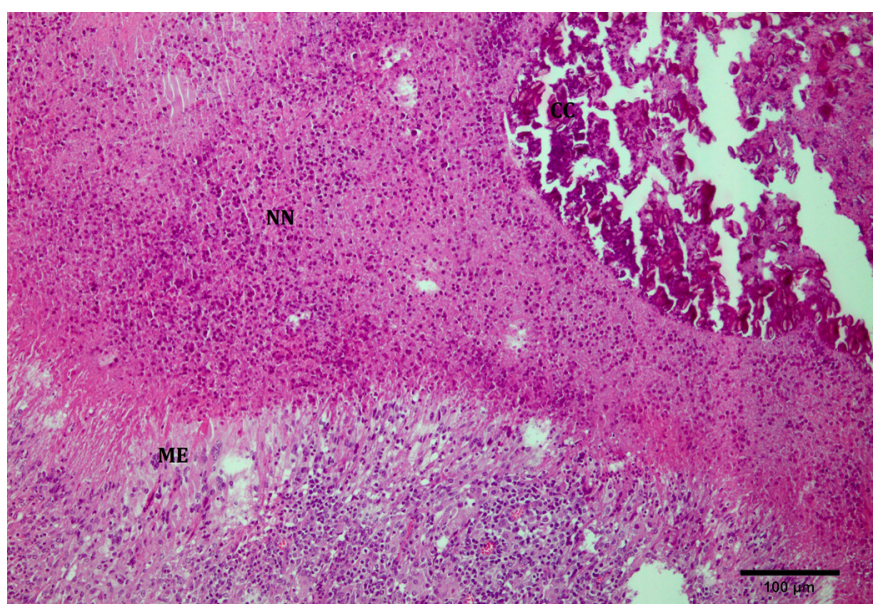

Fig.18. Cisticerco degenerado. 0 interior do cisto consiste de material necrótico (NN) contendo ao centro corpúsculos calcários (CC) e circundados por intensa reação inflamatória, composta por macrófagos epitelioides (ME) dispostos em paliçada.HE, obj.20x.

do parênquima dos cestoides, sendo especialmente proeminentes nos estágios larvares. Sua complexa composição química inclui o carbonato de cálcio (Eberhard \& Alcaraz 2006). Segundo alguns autores as características microscópicas que asseguram o diagnóstico de cisticercose incluem a mineralização linear, os histiócitos dispostos em paliçada circundando a área necrótica central e a presença de corpúsculos calcários (Santos 1984, Tortelly 2003, Eberhard \& Alcaraz 2006, Costa et al. 2012). As lesões microscópicas dos cisticercos vivos foram caracterizadas por uma vesícula circundada por histiócitos em paliçada e infiltrado inflamatório misto, com proliferação de tecido conjuntivo fibroso externamente. É comum o corte histológico incluir apenas a parede da vesícula do estágio larval, muitas vezes nesses casos, os corpúsculos calcários poderão ser a única característica diagnóstica que permite identificar o parasita como um cestoide (Eberhard \& Alcaraz 2006). Contudo, nos casos de cisticercose viva desse trabalho não foram observados esses corpúsculos calcários e o diagnóstico foi baseado na macroscopia e epidemiologia, uma vez que o restante do lote desses bovinos também possuía cisticercos, que foram confirmados microscopicamente.

\section{Esofagostomose}

Membros do gênero Oesophagostomum (filo Nemathelminthes, classe Nematoda, superfamília Strongyloidea) infectam ovinos, bovinos, caprinos e suínos (Brown et al. 2007). Classicamente, as larvas histotrópicas desses parasitas formam nódulos no intestino destes animais e são por isso comumente denominados vermes nodulares (Taylor et al. 2007). O. radiatum adultos parasitam principalmente $o$ intestino grosso de bovinos, mas as larvas migram e produzem nódulos na parede do intestino delgado. Os vermes adultos são brancos, delgados e de $10-22 \mathrm{~mm}$ de comprimento. Os machos são menores que as fêmeas $(12-17 \mathrm{~mm})$ (Taylor 2007). O bovino se infecta pela ingestão das larvas de estágio L3 que penetram na mucosa de qualquer parte do intestino delgado formando nódulos onde a muda para L4 ocorre (Fig.19). As L4 emergem na superfície da mucosa e migram para o cólon e se desenvolvem no estágio adulto. Numa reinfecção as larvas podem permanecer presas nos nódulos na forma de L4. 0 período pré-patente é de 40 dias. É difícil estabelecer a prevalência desse parasita a partir de dados de abatedouros, uma vez que esses estabelecimentos não classificam os parasitas intestinais separadamente (Brasil 2012).

Neste estudo, os nódulos parasitários variaram de tamanho na serosa intestinal, apresentando-se amarelos, algumas vezes com alo hiperêmico ao redor, e com um centro branco-acinzentado. Os esofagostomíneos são denominados vermes nodulares porque as larvas parasitas tendem a ficar encapsuladas por uma reação inflamatória um tanto exacerbada por parte de hospedeiros previamente sensibilizados (Fig.20). Com o tempo os nódulos caseificam-se e calcificam-se (Eberhard \& Alcaraz 2006). Ocasionalmente, nódulos de esofagostomíneos podem ser encontrados no fígado, pulmões, mesentério e linfonodos mesentéricos (Brown et al. 2007), semelhantemente ao que aconteceu em um dos casos, em que nódulos foram observados dis- 


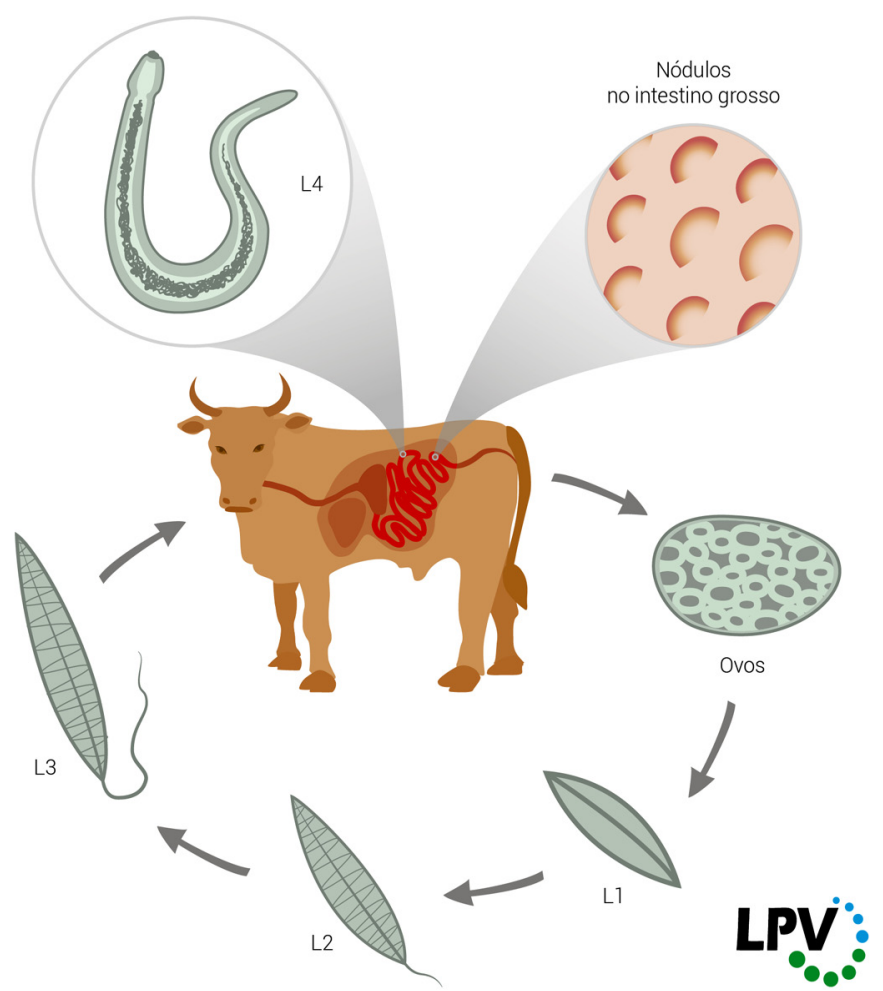

Fig.19. 0 ciclo de Oesophagostomum sp. é direto. 0 bovino elimina ovos embrionados que dão origem às larvas (L1-L3). Bovinos se infectam pela ingestão das larvas (L3) que penetram na mucosa de qualquer parte do intestino delgado formando nódulos. Nesses nódulos ocorre a muda para L4. As larvas emergem na superfície da mucosa e migram para o cólon e se desenvolvem no estágio adulto. Numa reinfecção as larvas L4 podem permanecer presas nos nódulos. 0 período pré-patente é de 40 dias.

tribuídos pelo omento, acarretando reação granulomatosa típica.

Microscopicamente, as lesões foram caracterizadas por piogranulomas, constituídos por um centro necrótico com neutrófilos e eosinófilos (Fig.21), rodeado por macrófagos

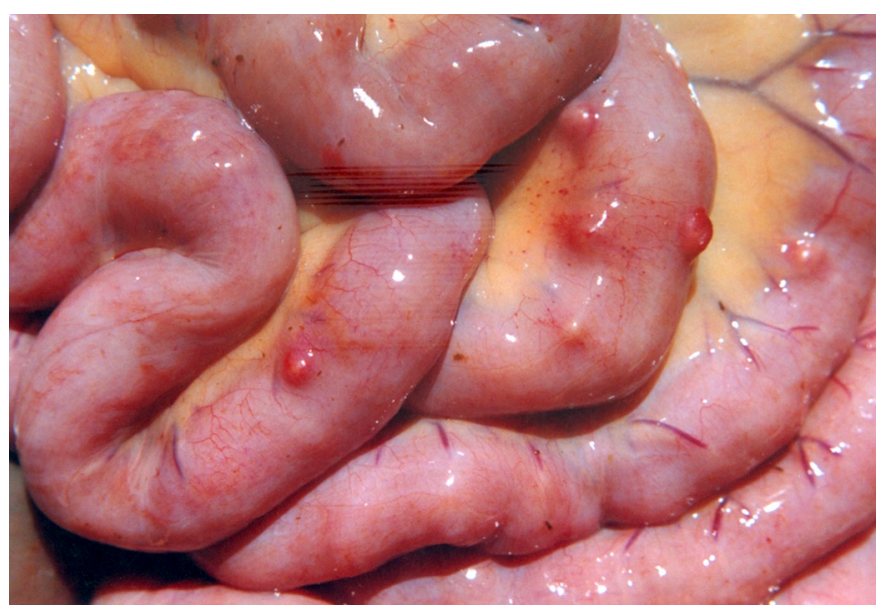

Fig.20. Múltiplos nódulos de Oesophagostomum sp. salientes na serosa do intestino delgado de um bovino. Esses parasitas são denominados vermes nodulares porque as larvas parasitas tendem a ficar encapsuladas por uma reação inflamatória desenvolvida por hospedeiros previamente sensibilizados. epitelioides, ocasionalmente, células gigantes multinucleadas, linfócitos e plasmócitos. Externamente havia proliferação de tecido conjuntivo fibroso. Em três casos a L4 ou seus remanescentes puderam ser vistos em cortes longitudinais e transversais na mucosa e submucosa intestinal, com intensa reação inflamatória eosinofílica e granulomatosa. 0 parasita era constituído por uma cutícula eosinofílica delgada, musculatura platimiariana e um trato digestivo e reprodutivo. Um dos intestinos estava intensamente afetado por piogranulomas; neste pôde-se perceber, ao redor dos restos parasitários, depósitos hialinos semelhante à reação de Splendore-Hoeppli (Fig.22). Esse fenômeno já foi descrito em casos de pitiose em cavalos (Mendonza 1987, Martins 2010) e é causado por eosinófilos que se aderem ao parasita. A participação dos eosinófilos é importante na reação inflamatória contra parasitas helmintos gastrointestinais (Day \& Schultz 2011) como O. radiatum. Esses vermes liberam uma série de moléculas proteicas (MP) que podem ser amostradas pelas células apresentadoras de antígeno (APCs), processadas e apresentadas aos linfócitos B nos folículos e aos linfócitos T na zona paracortical (linfócitos T) dos linfonodos mesentéricos. IgE específicas para as MP do helminto ocupam a superfície dos mastócitos. Quanto mais MP do helminto forem absorvidas através da membrana mucosa, farão uma ligação cruzada com essas moléculas de IgE levando a desgranulação dos mastócitos e subsequente

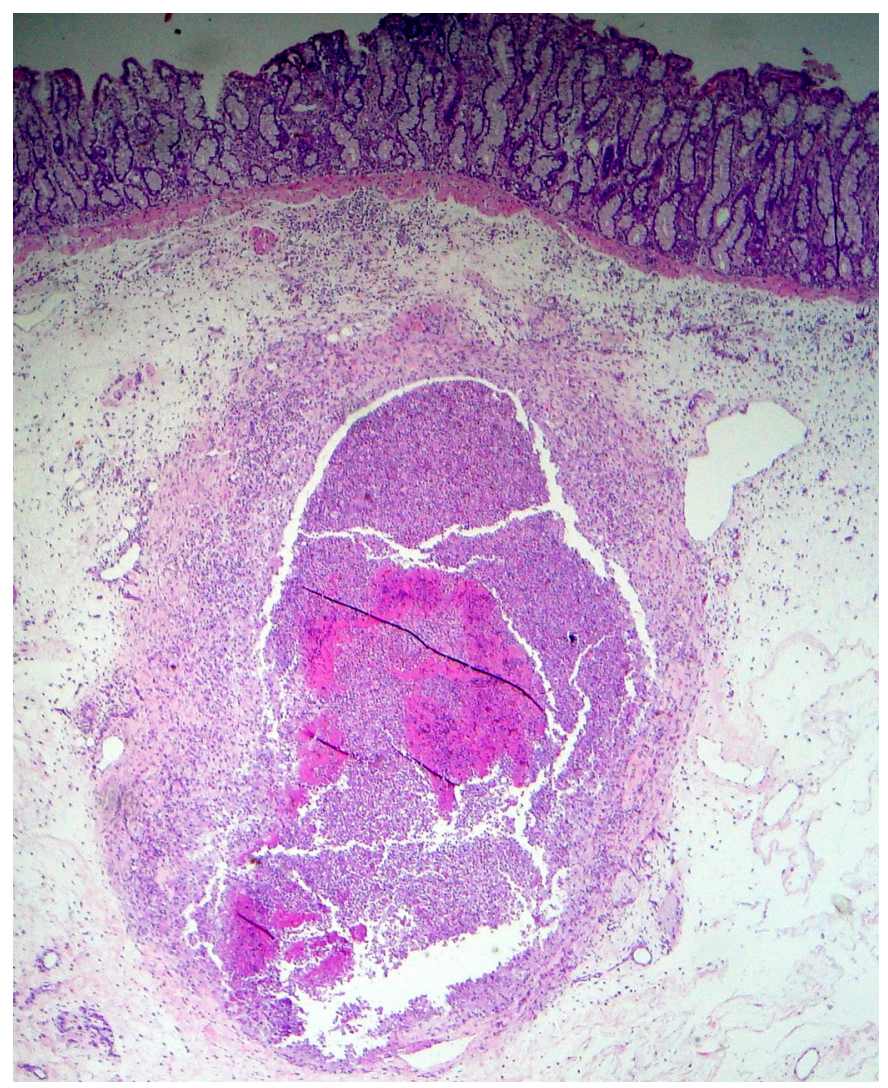

Fig.21. Aspecto microscópico da lesão mostrada na Figura 20. Um piogranuloma é observado na submucosa. 0 centro necrótico contém abundantes eosinófilos e neutrófilos. Em alguns casos é possível encontrar-se larvas L4 em meio ao exsudato inflamatório. HE, obj.10x. 


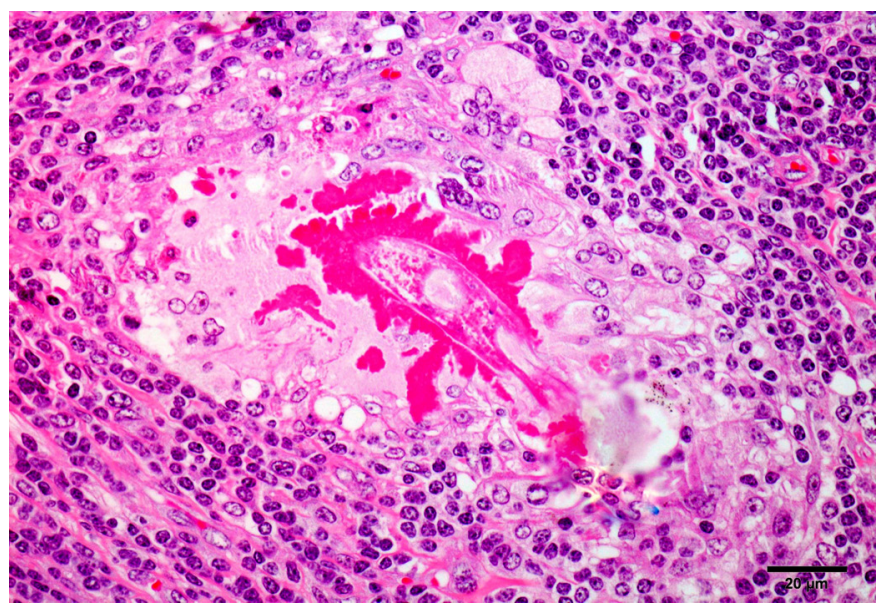

Fig.22. Esofagostomose. Aspecto microscópico do centro de um nódulo parasitário. Observam-se os restos de uma larva L4 rodeados de depósitos hialinos oriundos da desgranulação dos eosinófilos formando estruturas semelhantes às do fenômeno de Splendore-Hoeppli. Circundando essas estruturas observam-se macrófagos epitelioides, algumas células gigantes multinucleadas e abundantes linfócitos HE, obj.40x.

edema (vasodilatação) e migração de eosinófilos que são proeminentes nesses infiltrados inflamatórios. Os eosinófilos desgranulam localmente e os mediadores dos seus grânulos causam dano direto à cobertura do helminto.

\section{Euritrematose}

Espécies de Eurytrema (filo Plathyhelminthes, classe Trematoda, subclasse Digenea, família Dicrocoeliidae), vivem principalmente nos ductos pancreáticos e ocasionalmente nos ductos biliares de bovinos, búfalos, camelos, veados, cabras, ovinos, porcos e seres humanos (Ilha et al. 2005). No Brasil, E. coelomaticum é descrita como a espécie mais comum nos ductos pancreáticos de bovinos, ocorrendo, principalmente, nas regiões Central, Sudoeste e Sul (Travassos et al. 1969, Mattos Júnior \& Vianna 1987). 0 parasita requer dois hospedeiros intermediários para completar seu ciclo (Fig.23). No Brasil eles são o caramujo (Bradybaena similaris) e os gafanhotos do gênero Conocephalus (Mattos Júnior \& Vianna 1987). Os ovos são eliminados nas fezes e ingeridos pelo primeiro hospedeiro intermediário (B. similaris) onde duas gerações de esporocistos são formadas. Cerca de cinco meses após a infecção, a segunda geração de esporocistos produz cercárias que são liberadas na pastagem apenas algumas horas antes do amanhecer. As cercárias são então ingeridas pelo segundo hospedeiro intermediário (Conocephalus sp.). 0 bovino se infecta pela ingestão acidental de gafanhotos contaminados. As metacercáriasse excistam no duodeno, migram para o pâncreas via ductos pancreáticos acessórios e se distribuem pelos ductos pancreáticos tributários. A infestação dos ductos pancreáticos por Eurytrema spp. causa pancreatite intersticial crônica (Ilha et al. 2005).

Apesar da baixa prevalência de euritrematose nesse trabalho (dois casos), a ocorrência dessa parasitose em abatedouros brasileiros aumentou bastante nos últimos anos (Azevedo et al. 2004). Um estudo epidemiológico realizado em Minas Gerais relatou uma frequência de 17,15\% (Brant \& Costa 1963). Em outro relato, no estado de São Paulo, $70 \%$ dos bovinos abatidos apresentavam parasitismo pancreático por Eurytrema sp. (Mattos Júnior \& Vianna 1987).

Macroscopicamente, o tecido pancreático em um dos casos apresentava acentuada atrofia do parênquima e os ductos pancreáticos estavam espessados, contendo exemplares do trematoide (Fig.24). Em meio ao parênquima, observavam-se pequenos nódulos firmes e levemente avermelhados. No outro pâncreas havia apenas alguns ductos dilatados com exemplares do parasita e leve atrofia do parênquima. Relata-se que o tamanho dos trematoides adultos em meio às lesões é inversamente proporcional à intensidade destas lesões, provavelmente refletindo a falta de nutrientes para o verme devido à destruição tecidual (Barros 2011). Essa relação pôde ser estabelecida nos casos desse levantamento, no pâncreas em que a destruição tecidual foi mínima, os trematoides adultos eram grandes, ativos e restritos aos ductos maiores. Já no pâncreas gravemente danificado, os trematoides eram pequenos e atróficos e encontrados nos ductos menores.

Microscopicamente, as lesões pancreáticas caracterizaram-se por serem leves em um dos casos e acentuadas em outro. Exemplares de trematoides adultos foram observados no interior de ductos pancreáticos distendidos em ambos os pâncreas. Esses parasitas eram revestidos

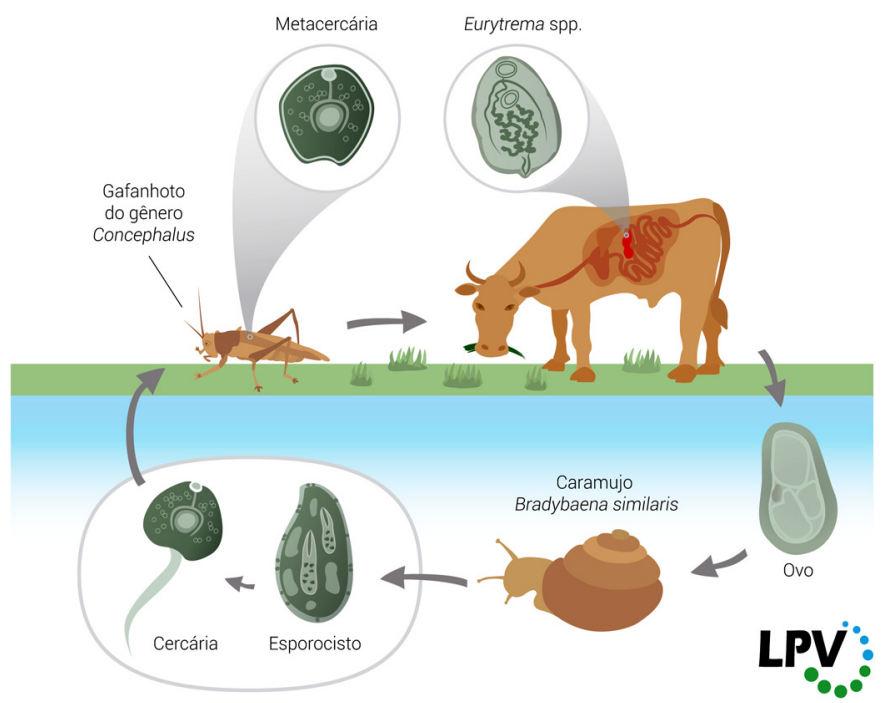

Fig.23. Eurytrema spp. necessitam dois hospedeiros intermediários para completar seu ciclo. No Brasil eles são o caramujo (Bradybaena similaris) e os gafanhotos do gênero Conocephalus. Os ovos são eliminados nas fezes e ingeridos pelo primeiro hospedeiro intermediário(B. similaris) onde duas gerações de esporocistos são formadas. Cerca de cinco meses após a infecção, a segunda geração de esporocistos produz cercárias que são liberadas na pastagem apenas algumas horas antes do amanhecer. As cercárias são então ingeridas pelo segundo hospedeiro intermediário (Conocephalus sp.). 0 bovino se infecta pela ingestão acidental de gafanhotos contaminados. As metacercárias se excistam no duodeno, migram para o pâncreas via ductos pancreáticos acessórios e se distribuem pelos ductos pancreáticos tributários. A infestação dos ductos pancreáticos por Eurytrema spp. causa pancreatite intersticial crônica. 
por um tegumento eosinofílico e não possuíam cavidade celômica, característica ausente na classe Trematoda (Gardiner \& Poynton 1999). Internamente observava-se trato digestivo e reprodutivo masculino e feminino. No interior do útero havia ovos não operculados, amarelos a marrons. Alguns ovos foram observados soltos no parênquima, próximos aos ductos, em torno deles havia marcada reação granulomatosa (Fig.25) caracterizada por macrófagos epitelioides e plasmócitos, resultados similares foram previamente descritos (Belém et al. 1994, Yamamura et al. 1995). No pâncreas gravemente afetado observava-se fibrose periductal e em áreas multifocais do parênquima, com infiltração de neutrófilos e eosinófilos. A proliferação de tecido fibroso (periductal e intersticial) é considerada a principal manifestação histológica de euritrematose em animais (Yamamura 1989). Essa proliferação, associada à obstrução ductal pelo parasita e seus ovos, induzem destruição dos ácinos glandulares, com consequente atrofia do parênquima, podendo resultar em áreas com infiltração

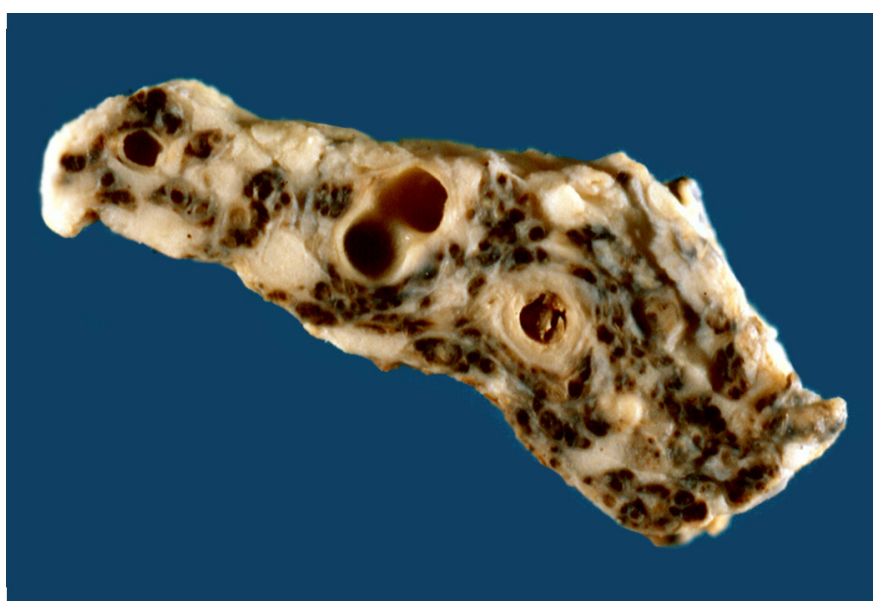

Fig.24. Marcada atrofia de pâncreas de bovino na euritrematose pancreática. Os ductos estão espessados, e repletos de exemplares de Eurytrema. As partes brancas correspondem a fibrose, as pares escura a aglomerados de trematoides.

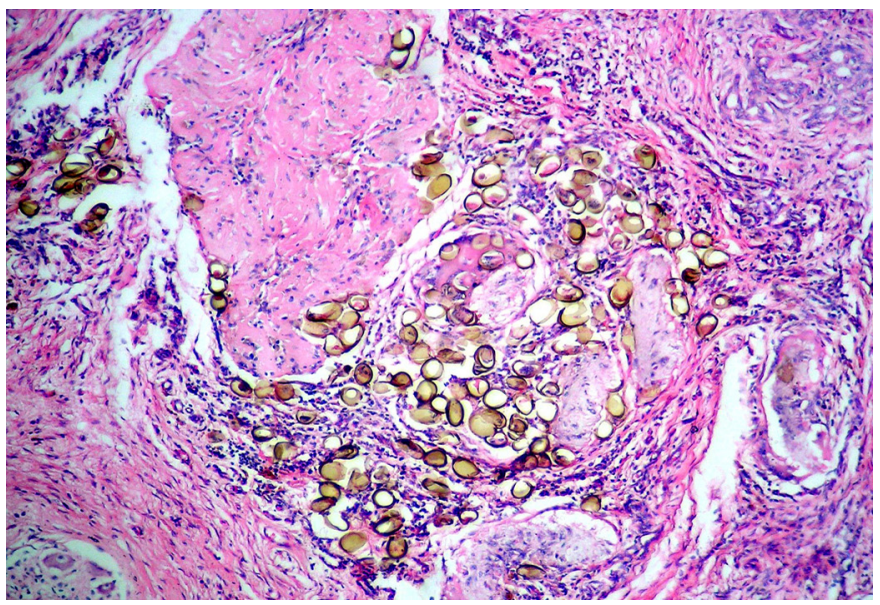

Fig.25. Histopatologia do pâncreas de bovina na euritrematose pancreática. Ovos ovais, refringentes e escuros de Eurytrema radiatum são vistos em meio à fibrose e reação inflamatória granulomatosa. Há considerável perda de parênquima pancreático. HE, obj.40x. gordurosa (Headleyet al. 2009). No pâncreas com a lesão inicial, a fibrose e o infiltrado inflamatório restringiam-se a região periductal. Hiperplasia do epitélio dos ductos foi observada em torno das áreas parasitadas, característica histológica frequentemente descrita nos casos de euritrematose (Headleyet al. 2009, Rachid et al. 2011). Uma síndrome esporádica de emagrecimento afetando bovinos do norte do Paraná , com perdas anuais de 1-3\% dos bovinos das áreas afetadas foi descrita e atribuída a Eurytrema pancreaticum (Ilha et al. 2005)

\section{Paranfistomíase}

Paramphistomum spp. (filo Plathyhelminthes, classe Trematoda, subclasse Digenea, família Paramphistomidae) são trematoides do rúmen e retículo de ruminantes. Ocasionalmente exemplares de Paramphistomum spp. podem ser encontrados no esôfago (Grist 2008). P. cervi é a espécie mais comumente encontrada (Grist 2008). A paranfistomíase é distribuída em todo o mundo, porém as mais altas prevalências têm sido relatadas em regiões tropicais e subtropicais que possuem as características climáticas necessárias para o desenvolvimento (Fig. 26) do parasita (Ozdalet al. 2010). 0 desenvolvimento no hospedeiro intermediário (caramujos do gênero Planorbis ou Bilinus) é semelhante ao da Fasciola e, sob condições favoráveis $\left(26-30^{\circ} \mathrm{C}\right)$, pode ser completado em quatro semanas. Após a ingestão das metacercárias encistadas junto com a grama, o desenvolvimento no hospedeiro final ocorre inteiramente no trato alimentar. Após o excistamento os trematoides jovens fixam-se no duodeno

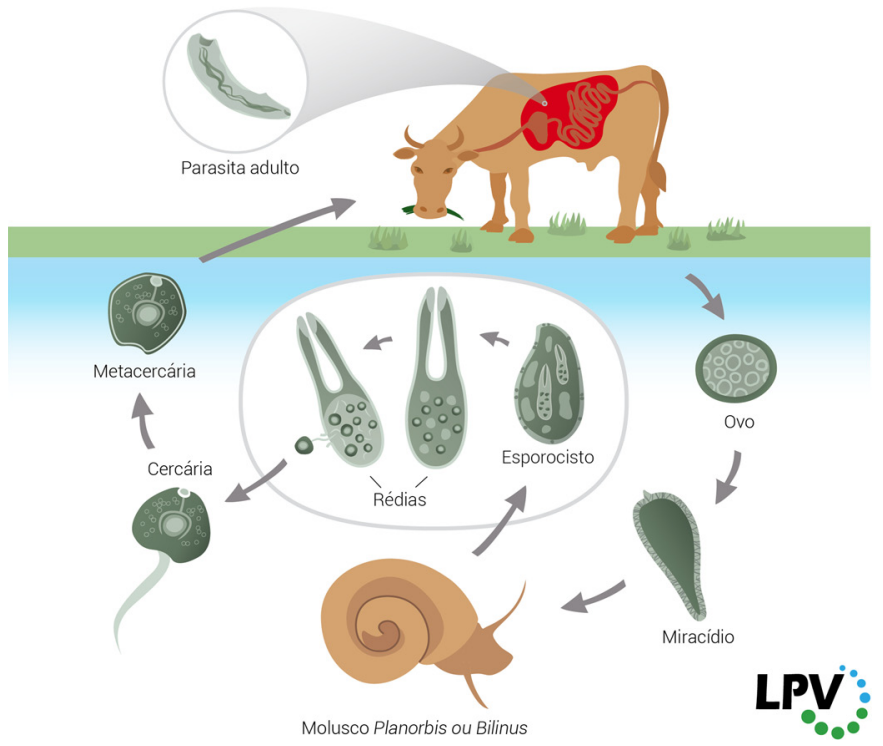

Fig.26. Ciclo evolutivo de Paramphistomum cervi. O desenvolvimento no hospedeiro intermediário (caramujos do gênero Planorbis ou Bilinus) é semelhante ao da Fasciola e, sob condições favoráveis de temperatura, pode ser completado em quatro semanas. Após a ingestão das metacercárias encistadas junto com a grama, o desenvolvimento no hospedeiro final ocorre inteiramente no trato alimentar. Após o excistamento os trematoides jovens fixam-se no duodeno e se alimentam aí por cerca de 6 semanas antes de migrarem em direção aos pré-estômagos onde se atingem os estágios maduros. 0 período pré-patente é de 7-10 semanas. 
e se alimentam aí por cerca de seis semanas antes de migrarem em direção aos pré-estômagos onde atingem os estágios maduros. 0 período pré-patente é de 7-10 semanas. Os parasitas nos pré-estômagos são bem tolerados, mesmo se milhares estão se alimentando no rúmen ou retículo, e não causam sinais clínicos (Rolfe \& Boray 1987, Taylor et al. 2007), embora algumas papilas possam se tornar atrofiadas, o que não foi observado no caso aqui relatado. Os efeitos patogênicos são associados ao estágio larval no intestino quando infestações duodenais pesadas por larvas de Paramphistomum spp. podem causar enterite, diarreia, anorexia, sede intensa, tenesmo e hemorragia retal, com mortalidade em surtos agudos chegando a 90\% (Taylor et al. 2007), principalmente em novilhos (Dutra 210). Nessa condição os achados morfológicos incluem enterite (Urquhart et al. 1996), caracterizada por congestão, edema e erosões na mucosa (Brown et al. 2007, Dutra 2010).

Em um estudo realizado em matadouros do Rio Grande do Sul (Mattos \& Ueno 1996), 26,3\% dos rúmens estavam parasitados porParamphistomumsp., sendo que em alguns municípios todos os animais destinados ao abate estavam parasitados. A distribuição geográfica desse trematoide no Rio Grande do Sul se assemelha à de Fasciola hepatica, localizando-se próximo as zonas fronteiriças com o Uruguai (Mattos \& Ueno 1996, Müller 2007). Dois fatores são responsáveis pela ocorrência de apenas um caso da paranfistomíase no presente estudo. Um deles é o não acompanhamento da inspeção do rúmen e retículo, que é realizado num local separado da inspeção dos outros órgãos, denominado coloquialmente "bucharia". O outro é que dificilmente um rúmen ou retículo parasitado com Paramphistomum spp. será destinado ao departamento de inspeção final, uma vez que esses são condenados rotineiramente na linha de inspeção pelos agentes responsáveis. Consequentemente, o acesso do médico veterinário a esses órgãos é limitado, sendo raramente os mesmos enviados para análise.

Os adultos de Paramphistomum spp. são pequenos $(1 \mathrm{~cm}$ de comprimento), cônicos, rosados, com uma ventosa visível em uma extremidade do cone e outra na base (Urquhart et al. 1996). Numerosos exemplares desse trematoide esta-

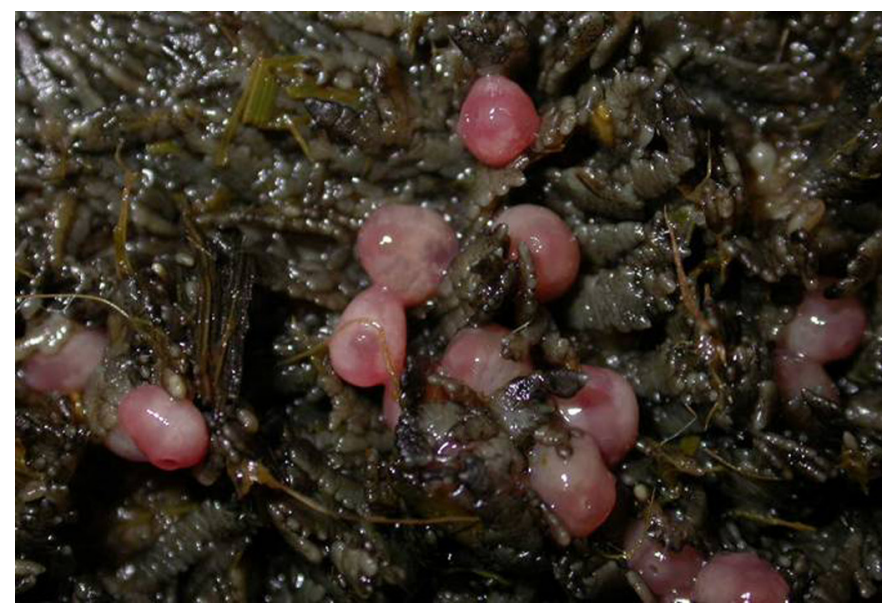

Fig.27. Exemplares de Paramphistomum cervi aderidos à mucosa do rúmen. Esses trematoides são róseos, brilhantes e têm a forma aproximada de uma gota ou pera.
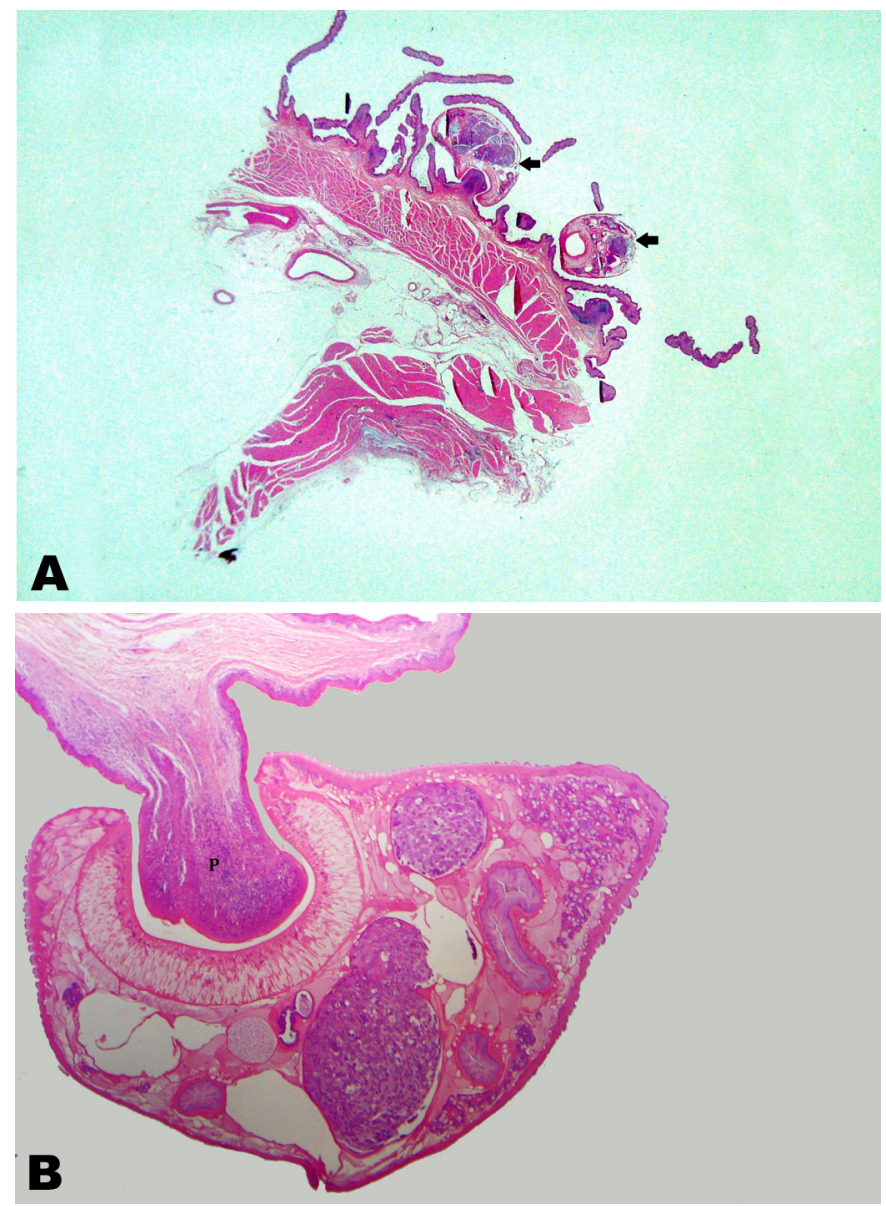

Fig.28. Microscopia do parasitismo por Paramphistomum cervi. (A) Dois exemplares de P. cervi (setas) aparecem aderidos à mucosa do rúmen. HE, obj.10x. (B) Maior aumento da lesão mostrada em A.Observa-se infiltrado inflamatório na papila (P) do rúmen onde o trematoide está aderido através de sua ventosa. HE, obj.40x.

vam aderidos à mucosa ruminal do caso encontrado neste estudo (Fig.27), sem causar qualquer alteração na mucosa. Esses parasitas adultos nos pré-estômagos são relativamente inofensivos

Na microscopia, observaram-se exemplares do parasita aderidos às papilas ruminais através de suas ventosas (Fig.28). Os trematoides adultos apresentam um tegumento eosinofílico com espinhos, trato digestivo e reprodutivo masculino e feminino (hermafroditas). Esses espinhos são frequentes na porção anterior do organismo, mas podem ser encontrados em todo tegumento (Gardiner \& Poyton 1999). As papilas ruminais afetadas apresentaram reação inflamatória constituída por linfócitos, plasmócitos, neutrófilos e alguns eosinófilos.

Agradecimentos.- A realização desse trabalho e o custo de sua publicação foram financiados pelo CNPq/Projeto Universal 482509/2012.

\section{REFERÊNCIAS}

Alberton G.C. 2000. Estudo anatomopatológico, microbiológico, citológico e físico das articulações com artrite no abatedouro. Tese de Doutorado em Medicina Veterinária, Faculdade de Medicina Veterinária e Zootecnia, Universidade Estadual Paulista, Botucatu. 81p. 
Alldred A.J. \& Nisbet N.W. 1964. Hydatid disease of bone in Australasia. J. Bone Joint Surg. 46B:260-267.

Azevedo J.R., Mannigel R.C., Agulhon A.Z., Borba T.R., Barbiéri A.W., Oliveira D.C.L., Headley S.A. \& Janeiro V. 2004. Prevalence and geographical distribution of bovine eurytrematosis in cattle slaughtered in northern Paraná, Brazil. Pesq. Vet. Bras. 24:23-26.

Barros C.S.L. 2011. Fígado, vias biliares e pâncreas exócrino, p.183-290. In: Santos R.L. \& Alessi A.C. (Eds), Patologia Veterinária. Roca, São Paulo.

Bassyouni A. \& Maher A. 1978. Hydatid cyst presenting as a quinsy. J. Laryngol. Otol. 92:729-734.

Beard T.C. 1976. The invisible worm. Lancet 308:811-812.

Belém P.A.D., Oliveira M.R., Padovani C.R. \& Luvizotto M.C.R. 1994. Alterações pancreáticas em bovinos naturalmente infectados por Eurytrema sp. e sua associação com a carga parasitária e o número de ovos por grama de fezes (OPG). Braz. J. Vet. Res. Anim. Sci. 31:273-281.

Brant P.C. \& Costa A.S. 1963. Distribuição geográfica da hidatidose, cisticercose, euritrematose, dictiocaulose e fasciolose nos bovinos no Estado de Minas Gerais. Arq. Esc. Vet., Belo Horizonte, 15:47-59.

Brasil 2011. Destino de matérias-primas e produtos por UF. Ministério da Agricultura, Pecuária e Abastecimento (MAPA),Brasília. 9p.

Brasil 2012. Destino de matérias-primas e produtos por UF. Ministério da Agricultura, Pecuária e Abastecimento (MAPA), Brasília. 11p.

Brasil 1980. Regulamento da Inspeção Industrial e Sanitária de Produtos de Origem Animal (Aprovado pelo decreto no 30690 , de 20.03.52, alterado pelo decreto $\mathrm{n} \times 1255$, de 25.06.52). R.I.I.S.P.O.A, Ministério da Agricultura, Brasília. 66p.

Brown C.C., Baker D.C. \& Barker I.K. 2007. Alimentary system, p.1-296.In: Maxie M.G. (Ed.), Jubb, Kennedy \& Palmer's Pathology of Domestic Animals. Vol.2. $4^{\text {th }}$ ed. Academic Press, San Diego.

Brown D.G. 2009. Georgis'Parasitology for Veterinarians. $9^{\text {th }}$ ed. Saunders Elsevier, St Louis.451p.

Cabrera P.A., Lloyd S., Haran G., Pineyro L., Parietti S., Gemmell M.A., Correa O., Morana A. \& Valledor S. 2002. Control of Echinococcus granulosus in Uruguay: evaluation of different treatment intervals for dogs. Vet. Parasitol. 103:333-340.

Campbell A.J., Sheers M., Moore R.J., Edwards S.R. \& Montague E. 1981. Proline biosynthesis by Fasciola hepatica at different development stages in vivo and in vitro. Molec. Biochem. Parasitol. 3:91-101.

Costa A.M.C.B. 2010. Fasciolose Bovina: aspectos clínicos e epidemiológicos no Alentejo. Dissertação de Mestrado Integrado em Medicina Veterinária, Faculdade de Medicina Veterinária da Universidade Técnica de Lisboa, Lisboa. 91p.

Costa R.F.R., Santos I.F., Nascimento E.R. \& Tortelly R. 2006. Caracterização das reações inflamatórias em corações de bovinos comercializados na cidade de Nova Friburgo/RJ. Revta Bras. Ciênc. Vet. 13:76-79.

Costa R.F.R., Santos I.F., Santana A.P., Tortelly R., Nascimento E.R., Fukuda R.T., Carvalho E.C.Q. \& Menezes R.C. 2012. Caracterização das lesões por Cysticercus bovis, na inspeção post mortem de bovinos, pelos exames macroscópico, histopatológico e pela reação em cadeia da polimerase (PCR). Pesq. Vet. Bras. 32:477-484.

Cringoli G., Rinaldi L., Musella V., Veneziano V., Maurelli M.P., Di Pietro F., Frisiello M. \& Di Pietro S. 2007. Geo-referencing livestock farms as tool for studying cystic echinococcosis epidemiology in cattle and water buffaloes from southern Italy. Geospatial Health 2:105-111.

Cunha F.O.V., Marques S.M.T. \& Mattos M.J.T. 2007. Prevalence of slaughter and liver condemnation due to Fasciola hepatica among sheep in the state of Rio Grande do Sul, Brazil 2000 and 2005. Parasitol. Latinoamericana 62:188-191.

Day M.J. \& Schultz R.D. 2011. The immune response to helminth infection, p.135. In: Ibid. (Eds), Veterinary Immunology: principles and practice. Mason Publishing, London.

Dutra F. 2010. Paramphistomiasis aguda em novillitosa. Archivo Veterinario del Este 7:1-2.

Dutra L.H., Molento M.B., Naumann C.R., Biondo A.W., Fortes F.S., Savio D. \& Malone J.B. 2010. Mapping risk of bovine fasciolosis in the south of Brazil using Geographic Information Systems. Vet. Parasitol. 169:76-81.
Eberhard M.L. \& Alcaraz A. 2006. Diagnóstico histopatológico, p.359-394. In: Bowman D.D. (Ed.), Parasitologia Veterinária de Georgis. 8ª ed. Manole, Barueri.

Freitas M.R. 1999. Caracterização anatomopatológica de bursites cervicais de bovinos abatidos sob Inspeção Federal no estado de Goiás. Dissertação de Mestrado em Ciência Animal, Escola de Veterinária, Universidade Federal de Goiás, Goiânia. 65p.

Gardiner C.H. \& Poyton S.L. 1999. An Atlas of Metazoan Parasites in Animal Tissues. Armed Forces Institute of Pathology, Washington, DC. 64p.

Grist A. 2008. Bovine Meat Inspection. $2^{\text {nd }}$ ed. Nottingham University Press, Nottingham. 278p.

Headley S.A., Saut J.P.E., Bassani C.A., Sangioni L.A., Birgel Junior E.H. \& Yamamura M.H. 2009. Histopathologic patterns of pancreatic lesions induced by Eurytrema coelomaticum in cattle from the central-west region of the State of Paraná, Southern Brazil. Braz. J. Vet. Pathol. 2:3-7.

IBGE 2006. Censo Agropecuário. Instituto Brasileiro de Geografia e Estatística. <http://www.ibge.gov.br> Acessado em 20 de abril de 2013.

Ilha M.R.S., Loretti A.P. \& Reis A.C.F. 2005. Wasting and mortality in beef cattle parasitized by Eurytrema coelomaticum in the State of Paraná, southern Brazil. Vet. Parasitol. 133:49-60.

Irabuena O.,Nieto A., Ferreira A.M., Battistoni J. \& Ferragut G. 2000. Characterization and optimization of bovine Echinococcus granulosus cyst fluid to be used in immunodiagnosis of hydatid disease by Elisa. Revta Inst. Med. Trop., São Paulo, 42:255-262.

Infante Gil J. \& Costa Durão J. 1990. Introduction, p.5-7. In: Ibid. (Eds), A Colour Atlas of Meat Inspection. Fundação Calouste Gulbenkian, Lisboa. $453 p$.

Isseroff H., Spengler R.N. \& Charnock D.R. 1979. Fasciolosis: Similarities of the anemia in rats to that produced by infused proline. J. Parasitol. 65:709-714.

Kelly W.R. 1993. The liver and biliary system: helminthic infections of liver and bile ducts, p.319-406. In: Jubb K.V.F., Kennedy P.C. \& Palmer N. (Eds), Pathology of Domestic Animals. Vol.2. $4^{\text {th }}$ ed. Academic Press, San Diego.

Kul O. \& Yildiz K. 2010. Multivesicular cysts in cattle: characterization of unusual hydatid cyst morphology caused by Echinococcus granulosus. Vet. Parasitol. 170:162-166.

Marcos L.A., Yi P., Machicado A., Andrade R., Samalvides F., Sánchez J. \& Terashima A. 2007. Hepatic fibrosis and Fasciola hepatica infection in cattle. J. Helminthol. 81:381-386.

Marques G.M., Buzi K.A., Galindo L.A., Baldini E.D. \& Biondi G.F. 2008. Avaliação dos registros de condenação por cisticercose em bovinos abatidos em frigoríficos da região centro oeste do estado de São Paulo, 1996 a 2000. Vet. Zootec. 15:114-120.

Martins T.B. 2010. Morfologia comparada da pitiose em cavalos, cães e bovinos. Dissertação de Mestrado do Programa de Pós-Graduação em Medicina Veterinária, Universidade Federal de Santa Maria, Santa Maria. 104p.

Mattos Junior D.G. \& Vianna S.S.S. 1987. O Eurytrema coelomaticum (Trematoda: Dricocoeliidae) no Brasil. Arq. Flum. Med. Vet. 2:3-7.

Mattos M.J.T. \& Ueno H. 1996. Prevalência de Paramphistomum no rúmen e retículo de bovinos no Estado do Rio Grande do Sul, Brasil. Ciência Rural 26:273-276.

Mattos M.J.T. de, Ueno H., Gonçalves P.C. \& Almeida J.E.M. de. 1997. Ocorrência estacional e bioecologia de Lymnaea columella Say, 1817 em habitat natural no Rio Grande do Sul. Revta Bras. Med. Vet.19:248-52.

Mendonza L. 1987. Pitiosis: uma revisión. Revta Ibér. Micol.4:159-175.

Monlux S.W. \& Monlux A.W. 1972. Atlas of Meat Inspection Pathology. Department of Agriculture, Washington, DC.

Morar R. \& Feldman C. 2003. Pulmonary echinococcosis. Eur. Respir. J. 21:1069-1077

Moreira M.D., Almeida L.P., Reis D.O. \& Santos W.L.M. 2002. Cisticercose bovina: um estudo com bovinos abatidos em matadouro municipal de Uberlândia, MG. Higiene Alimentar 16:37-41.

Müller G. 2007. Fasciolose, p.639-650. In: Riet-Correa F., Schild A.L., Lemos R.A.A. \& Borges J.R.J. (Eds), Doenças de Ruminantes e Equinos. Vol.1. 4a ed. Pallotti, Santa Maria. 722p. 
Ozdal N., Gul A. \& Deger S. 2010. Prevalence of Paramphistomum infection in cattle and sheep in Vanprovince, Turkey. Helminthologia 47:20-24.

Pawlowski Z. \& Schultz M.G. 1972. Taeniasis and cysticercosis (Taenia saginata). Adv. Parasitol. 10:269-343.

Pereira M.A.V.C., Schwanz V.S. \& Barbosa C.G. 2006. Prevalência da cisticercose em carcaças de bovinos abatidos em matadouros-frigoríficos do Estado do Rio de Janeiro, submetidos ao controle do Serviço de Inspeção Federal (SIF-RJ), no período de 1997 a 2003. Arqs Inst. Biológico, São Paulo, 73:83-87.

Prata L.F. \& Fukuda R.T. 2001. Fundamentos de Higiene e Inspeção de carnes, p.5-11. Funep, Jaboticabal, São Paulo.

Rachid M.A., Aquino-Neto H.M., Facury-Filho E.J., Carvalho A.U., Valle G.R. \& Vasconcelos A.C. 2011. Chronic interstitial pancreatitis and chronic wasting disease caused by Eurytrema coelomaticum in Nelore cow. Arq. Bras. Med. Vet. Zootec. 63:741-743.

Rolfe P.F. \& Boray J.C. 1987. Chemotherapy of paramphistomiasis in cattle. Aust. Vet. J. 64:328-334.

Santos I.F. 1984. Diagnóstico da cisticercose bovina em matadouros: novas técnicas de exame de esôfago e diafragma. Tese de Doutorado, Faculdade de Veterinária, Universidade Federal Fluminense, Niterói. 127p.

Santos R.E.V. 2002. Exame post mortem pela técnica de Santos, no estudo da prevalência da cisticercose bovina em matadouros do Estado do Rio de Janeiro, comparada à utilizada pelo serviço de inspeção estadual. Dissertação de Mestrado em Medicina Veterinária, Faculdade de Veterinária, Universidade Federal Fluminense, Niterói. 64p.

Santos R.E.V., Santos I.F. \& Bonisson J.C. 2003. Estudo comparativo entre a técnica post mortem de Santos e a do serviço de inspeção estadual para detecção de Cysticercus bovis em matadouros no Estado do Rio de Janeiro, Brasil. Revta Bras. Ciênc. Vet. 10:175-181.

Santurio J.M., Silva S.F., Beck A.A., Madeira P.C.O. \& Arend S. 1988. Determinação da inviabilidade do Cysticercus bovis em carcaças de bovinos submetidas ao tratamento pelo frio. Hora Vet. 8:13-18.

Scala A., Varcasia A. \&Garippa G. 2004. Cystic echinococcosis in Sardinia: the current role of sheep. Parasitologia 46:397-400.

SEAPA 2010. Secretaria da Agricultura, pecuária e Agronegócio. <http:// www2.agricultura.rs.gov.br/uploads/1294316729Dados_populacionais_do_rebanho_ovino_gaucho.pdf> Acessado em 10 de abril de 2013.

Souza V.K., Pessôa-Silva M.C., Kowalcsuk M., Marty S. \& Thomaz-Soccol V. 2007. Regiões anatômicas de maior ocorrência de Cysticercus bovis em bovinos submetidos à inspeção federal em matadouro-frigorífico no município de São José dos Pinhais, Paraná, de julho a dezembro de 2000. Rev. Bras. Parasitol. Vet. 16:92-96.

Stalker M.J. \& Hayes M.A. 2007. Liver and biliary system, p. 297-388. In: Maxie M.G. (Ed.), Jubb, Kennedy \& Palmer's Pathology of Domestic Animals. Vol.2. $4^{\text {th }}$ ed. Academic Press, San Diego.

Tanimoto T., Shirota K., Ohtsuki Y. \& Araki K. 1998. Eosinophilic proliferative pylephebitis in the liver of japanese beef cattle with fascioliasis. J. Vet. Med. Sci. 60:1073-1080.

Taylor M.A., Coop R.L. \& Wall R.L. 2007. Veterinary Parasitology. $3^{\text {rd }}$ ed. Blacwell, Oxford. 874p.

Teichmann D., Grobusch M.P., Gobels K., Muller H.P., Koehler W. \& Suttorp N. 2000. Acute fascioliasis with multiple liver abscesses. Scand.J. Infect. Dis. 32:558-560.

Togerson P.R. \& Budke C.M. 2003. Echinococcosis: an international public health challenge. Res. Vet. Sci.74:191-202.

Tortelly R. 2003. Lesões em fígados de bovinos sob Inspeção Sanitária e sua importância em Saúde Pública. Tese de Doutorado, Instituto de Veterinária, Universidade Federal Rural do Rio de Janeiro, Seropédica. 95p.

Travassos L., Freitas J.F.T. \& Kohn A. 1969. Trematóideos do Brasil. Mem. Inst. Oswaldo Cruz 67:11-886.

Ungar M.L., Germano M.I.S., Biggi G.S. \& Germano P.M.L. 1990. 0 valor dos registros de matadouros para Saúde Pública. Revta Cient. Fac. Vet. USP 14:91-97.

Urquhart G.M., Armour J., Duncan J.L., Dunn A.M. \& Jennings F.W. 1996. Veterinary Parasitology. $2^{\text {nd }}$ ed. Blackwell, Oxford. 307p.

Walther M. \&Koske J.K. 1980.Taenia saginata cysticercosis: a comparision of routine meat inspection and carcass dissection results in calves. Vet. Rec. 106:401-402.

Wilson W.G. 2005. Wilson's Practical Meat Inspection. $7^{\text {th }}$ ed. Blackwell, Oxford. 306p.

Yamamura M.H. 1989. Algumas avaliações sobre a patologia e controle da euritrematose bovina. Tese de Doutorado em Medicina Veterinária, Parasitologia Veterinária, área de concentração Helmintologia Veterinária, Universidade Federal Rural do Rio de Janeiro, Rio de Janeiro. 128p.

Yamamura M.H., Horner M.R. \& Lopes C.W.G. 1995. Avaliação patológica da euritrematose em bovinos naturalmente infectados na região de Londrina, Paraná. Semina, Ciênc. Agrár. 16:89-99. 